\title{
Measurement of Proton Spin Diffusivity in Hydrated Cementitious Solids
}

\author{
Brennan J. Walder, ${ }^{a}$ Nathan A. Prisco, ${ }^{b}$ Federico M. Paruzzo, ${ }^{a}$ Jayasubba Reddy Yarava, ${ }^{a}$ Bradley F. Chmelka, \\ Lyndon Emsley ${ }^{\text {a* }}$
}

${ }^{a}$ Institut des Sciences et Ingénierie Chimiques, École Polytechnique Fédérale de Lausanne (EPFL), CH-1015 Lausanne, Switzerland.

${ }^{\text {b}}$ Department of Chemical Engineering, University of California, Santa Barbara, California 93106, United States

Supporting Information Placeholder

ABSTRACT: The study of hydration and crystallization processes involving inorganic oxides is often complicated by poor long-range order and the formation of heterogeneous domains or surface layers. In solid-state $\mathrm{NMR},{ }^{1} \mathrm{H}^{-}{ }^{1} \mathrm{H}$ spin diffusion analyses can provide information on spatial composition distributions, domain sizes, or miscibility in both ordered and disordered solids. Such analyses have been implemented in organic solids, but crucially rely on separate measurements of the ${ }^{1} \mathrm{H}$ spin diffusion coefficients in closely related systems. We demonstrate that an experimental NMR method, in which "holes" of well-defined dimensions are created in proton magnetization, can be applied to determine spin diffusion coefficients in cementitious solids hydrated with ${ }^{17} \mathrm{O}$ enriched water. We determine proton spin diffusion coefficients of 240 $\pm 40 \mathrm{~nm}^{2} / \mathrm{s}$ for hydrated tricalcium aluminate and $140 \pm 20$ $\mathrm{nm}^{2} / \mathrm{s}$ for hydrated tricalcium silicate under quasi-static conditions.

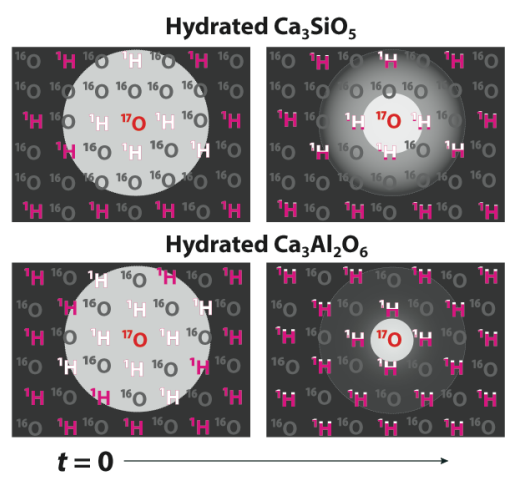

Solid-state NMR can often resolve different components of a mixture and is a method of choice for characterizing complex domains on the nanoscale..$^{1-2}$ Conventional examples include characterization of domain sizes in heterogeneous and semi-crystalline polymers and spatial composition distributions in lipid membranes. ${ }^{3-5}$ Recent advances involving the relay of nuclear hyperpolarization through interfaces ${ }^{6-7}$ as generated by dynamic nuclear polarization ${ }^{8-10}$ are proving particularly effective in this regard. In such experiments, proton hyperpolarization in one phase sets up large magnetization gradients at interfaces with a second phase of interest. As hyperpolarization builds up outside the second phase, efficient proton spin diffusion spontaneously and simultaneously transports magnetization into it. Magnetization gradients large enough to permit domain size analysis can also be established by domain selective enhancement of relaxation by doping with paramagnetic species ${ }^{11}$ or by selective saturation. ${ }^{3,12-}$ 14

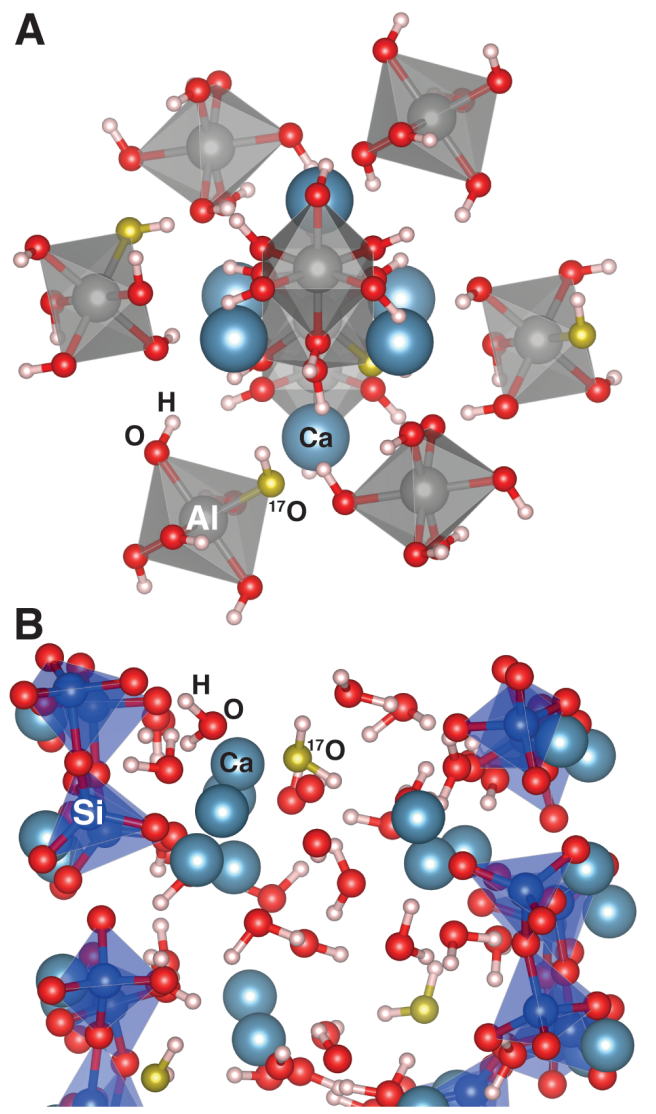

Figure 1. Schematic structures of hydrated tricalcium aluminate (A) and hydrated tricalcium silicate (B). By using water isotopically enriched in ${ }^{17} \mathrm{O}$ (golden atoms), spin labels are introduced that permit controllable burning of holes in the ${ }^{1} \mathrm{H}$ magnetization density. 

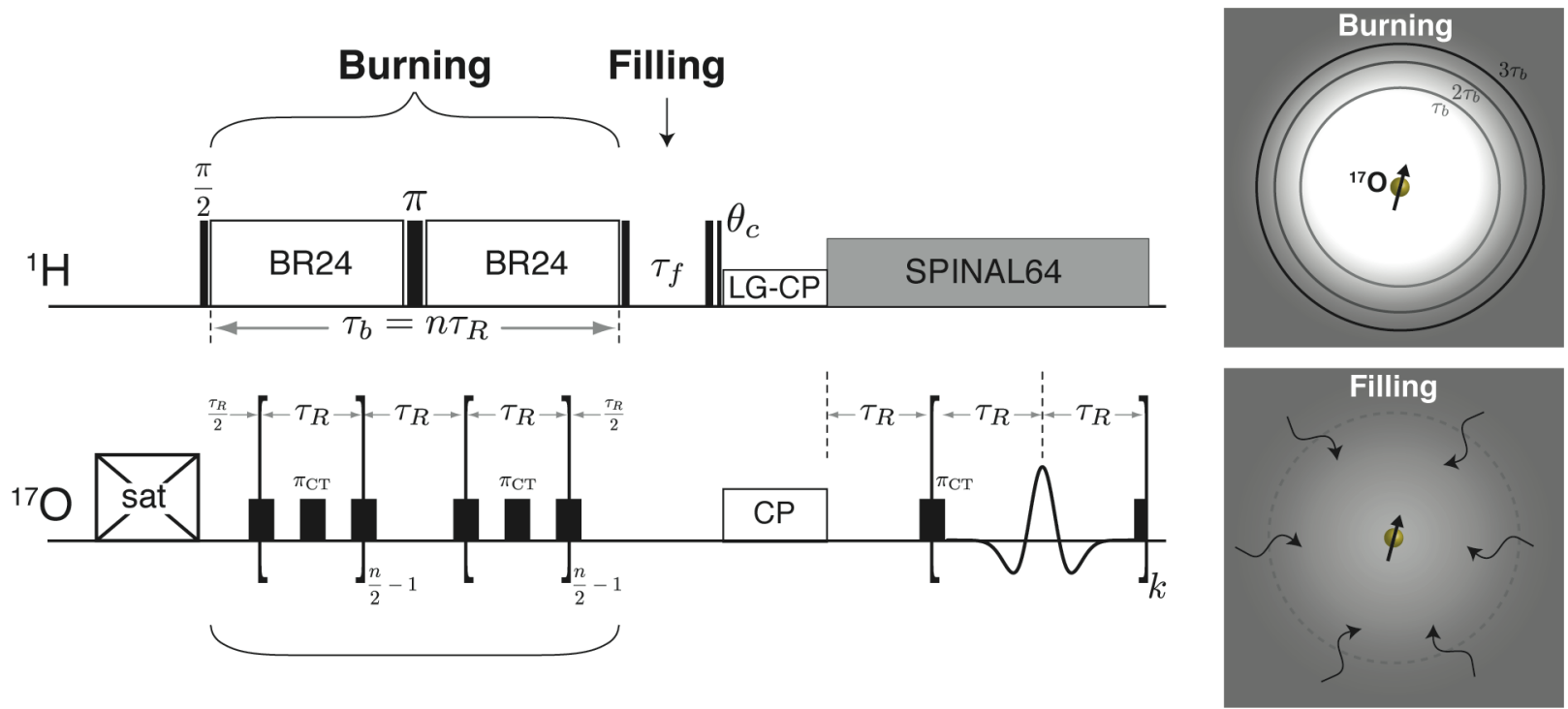

Figure 2. Hole-burning pulse sequence used for measuring proton spin diffusion coefficients in cementitious solids, based on the pulse sequence introduced by Chen and Schmidt-Rohr. ${ }^{15}$ During the hole-burning interval, REDOR ${ }^{16}$ pulses that are selective for the ${ }^{17} \mathrm{O}$ central transition $\left(\pi_{\mathrm{CT}}\right)$ are used to dephase the polarization of nearby protons $\left({ }^{1} \mathrm{H}\right)$. This is represented by a "hole", the radius of which grows in proportion to $\tau_{b}^{1 / 3}$. This is depicted in the tile labeled "Burning", where the proton magnetization is depicted as a gray continuum. During this step, homonuclear ${ }^{1} \mathrm{H}$ decoupling is applied to suppress proton spin diffusion to validate the use of spin-pair dephasing principles for calculating the spatial profile of the hole. During the hole-filling interval, magnetization returns to the ${ }^{17} \mathrm{O}$ nucleus by spontaneous proton spin diffusion, as illustrated in the tile labeled "Filling". Following this, the ${ }^{1} \mathrm{H}$ magnetization near the center of the hole is monitored by magnetization transfer to ${ }^{17} \mathrm{O}$ using a short $(10 \mu \mathrm{s}) \mathrm{CP}$ contact pulse with LG irradiation ${ }^{17}$ of ${ }^{1} \mathrm{H}$ rf to again suppress proton spin diffusion during the transfer. Multiple-echo acquisition with $\mathrm{CPMG}^{18}$ is used to enhance sensitivity. The signal intensity is analyzed as a function of $\tau_{f}$ for different $\tau_{b}$ to determine the proton spin diffusion coefficient $D_{H}$ using an analytic diffusion model. In all our experiments the sample rotation period for magic-angle spinning, $\tau_{R}$, was $0.33 \mathrm{~ms}$. Additional experimental details are given in the supplementary information.

Such domain size analyses rely on knowledge of proton spin diffusion coefficients, $D_{H}$, which are usually estimated based upon proton density or chemical similarity in the rigid limit. In more complex systems (e.g., calcium silicate or aluminate hydrates), structural disorder, chemical heterogeneity, or molecular mobility of intralayer water may influence $D_{H}$ values. An experimental determination of proton spin diffusion coefficients usually depends on prior knowledge of the length scale of initial magnetization gradients, $L$, as the NMR observables are functions not of $D_{H}$ alone, but rather the characteristic diffusion time $L^{2} / D_{H}$. In many cases, $L$ is governed by the sizes of the domains being studied and is thereby connected to the unknown parameters of prior interest. In most systems, domain sizes cannot be reliably controlled, which prevents direct measurement of spin diffusion coefficients.

Here we show this paradox can be overcome for silicates with an NMR experiment that burns "holes" of well-defined size in proton magnetization, ${ }^{15,19}$ thus establishing $L$ regardless of any particular chemical character of the hydrated phase. The experiment we develop here is based upon the method introduced by Chen and Schmidt-Rohr, ${ }^{15}$ which utilizes spin-pair dephasing in order to burn approximately spherical holes in the proton magnetization. The holes can exceed $1 \mathrm{~nm}$ in diameter, and subsequent hole filling by spin diffusion could be monitored through the same nucleus (in their case, ${ }^{13} \mathrm{C}$ ) used to burn the hole, provided a proton was bonded to it. In adapting their approach to cementitious solids, specifically tricalcium aluminate $\left(\mathrm{Ca}_{3} \mathrm{Al}_{2} \mathrm{O}_{6}\right)$ and tricalcium silicate $\left(\mathrm{Ca}_{3} \mathrm{SiO}_{5}\right)$ after hydration, we chose to use ${ }^{17} \mathrm{O}$ nuclei (as shown in Figure 1) for hole burning, due to ease of incorporation using ${ }^{17} \mathrm{O}$-enriched water and because hydrogen bonds to oxygen. These structural characteristics are illustrated in Figure 1.

Our implementation of the hole-burning pulse sequence under slow magic-angle spinning (MAS) is shown in Figure 2. Following saturation of ${ }^{17} \mathrm{O}$ magnetization, the magnetic dipoles of ${ }^{17} \mathrm{O}$ nuclei are used to destroy nearby ${ }^{1} \mathrm{H}$ magnetization. The application of a homonuclear proton decoupling method during dephasing, such as the BR-24 technique used here, ${ }^{22}$ is essential in two ways. First, it arrests proton spin diffusion. Second, it allows the dephasing dynamics to be approximated by spin-pair processes. Under these two conditions, a hole is burned in the proton magnetization. Chen and Schmidt-Rohr defined the radius of the hole to be the distance from the heteronucleus at which the ${ }^{1} \mathrm{H}$ magnetization rises to half the value it reaches well outside of the hole, ${ }^{15}$ 


$$
r_{0.5}=\sqrt[3]{\frac{5}{4} Q \tau_{b}},
$$

where $\tau_{b}$ is the hole-burning interval and $Q$ is a dephasing constant,

$$
Q=\lambda_{c S} h \frac{\mu_{0}}{4 \pi} \frac{\left|\gamma_{I} \gamma_{S}\right|}{4 \pi^{2}}
$$

which depends on the scaling factor $\lambda_{c s}$ accounting for the attenuation of the ${ }^{1} \mathrm{H}-{ }^{17} \mathrm{O}$ heteronuclear dipolar interaction by BR-24, the gyromagnetic ratios of the $I$ and $S$ spins, and the fundamental constants $\mu_{0}$ and $h$. The $S$ spin here, ${ }^{17} \mathrm{O}$, is quadrupolar $(S=5 / 2)$, but because central transition selective $\pi$ pulses were used (labeled $\pi_{\mathrm{CT}}$ in Figure 2), Eq. (2) remains valid. ${ }^{23}$ Taking $\lambda_{c s}=0.38$ for BR-24, ${ }^{24}$ we calculate $Q=6.2 \AA^{3} / \mathrm{ms}$ for our implementation of pairwise ${ }^{1} \mathrm{H}-{ }^{17} \mathrm{O}$ dipolar dephasing.

Following the hole-burning interval, the proton magnetization refills the hole by spontaneous proton spin diffusion. Under the experimental conditions used, transport of proton magnetization is, to a good approximation, governed by the isotropic diffusion equation

$$
\frac{\partial M}{\partial t}=D_{H} \nabla^{2} M
$$

where $M$ is a scalar field representing the longitudinal proton magnetization density and $D_{H}$ is the isotropic proton spin diffusion coefficient. If the ${ }^{17} \mathrm{O}$ spin labeling is sparse, we can solve Eq. (3) assuming the holes are far enough apart to be treated as an ensemble of isolated, spherically symmetric wells, which yields $M(r, t)$ as a function of the radial coordinate and time. The solution for the recovery of magnetization at the center of a spherical well, defined by the boundary conditions,

$$
\begin{gathered}
M(r, 0)=\left\{\begin{array}{l}
M_{1} \text { if } r<R, \\
M_{2} \text { if } r>R,
\end{array}\right. \\
\left.\frac{\partial M}{\partial r}\right|_{r=0}=0, \forall t, \\
\lim _{r \rightarrow \infty} M(r, t)=M_{2}, \forall t,
\end{gathered}
$$

is given by

$$
\begin{aligned}
& M(0, t)=M_{2}+\left(M_{1}-M_{2}\right)\left[\operatorname{erf}\left(\frac{R}{\sqrt{4 D_{H} t}}\right)-\right. \\
& \left.\frac{R}{\sqrt{\pi D_{H} t}} \exp \left(-\frac{R^{2}}{4 D_{H} t}\right)\right] .
\end{aligned}
$$

The spherical well profile is defined by an abrupt change of magnetization from $M_{1}$ within the burned hole to the bulk polarization value $M_{2}$ at the edge of the hole at $r=R$. While such an initial profile of magnetization is unrealistic, the solution can be adapted for an initial profile that features a smoother transition across the edge by introducing the advancement parameter, $\Delta t$, and making the substitution $t \rightarrow$ $t+\Delta t$ in Eq. (4). In this way, the initial profile is modeled as the solution of diffusion into a spherical well at a nonzero time $t=\Delta t$, and Eq. (3) does not need to be solved for a more complicated set of boundary conditions. ${ }^{15}$

As discussed, Eq. (3) does not possess a term corresponding to a magnetization sink. In reality, our data is affected by longitudinal ${ }^{1} \mathrm{H}$ spin relaxation, characterized by the time constant, $T_{1}$, which is on the order of milliseconds. The effects of relaxation, however, become significant only after most of the magnetization has returned to the hole by diffusion (vide infra), such that the behavior of magnetization exists approximately in two separate regimes, one diffusion dominated and one relaxation dominated. For the latter case, the magnetization behaves like $M(t)=M_{0} \exp \left(-t / T_{1}\right)$ for some initial value of magnetization $M_{0}$. Given this approximate separability, we take $M_{0}$ to be equal to Eq. (4), in spite of its time dependence.

Putting all of this together, we obtain the following analytic expression to model the magnetization recovery data,

$$
\begin{gathered}
M_{c}\left(\tau_{f}\right)=\left[M_{2}+\left(M_{1}-M_{2}\right)\left[\operatorname{erf}\left(\frac{R}{\sqrt{4 D_{H}\left(\tau_{f}+\Delta t\right)}}\right)-\right.\right. \\
\left.\left.\frac{R}{\sqrt{\pi D_{H}\left(\tau_{f}+\Delta t\right)}} \exp \left(-\frac{R^{2}}{4 D_{H}\left(\tau_{f}+\Delta t\right)}\right)\right]\right] \exp \left(-\frac{\tau_{f}}{T_{1}}\right),
\end{gathered}
$$

where the signal dependence on the parameter $\tau_{f}$ has now been made explicit. We see from this expression that hole filling data can be analyzed for $M_{1}, M_{2}, \Delta t, T_{1}$, and the characteristic diffusion time $R^{2} / D_{H}$. For our calculations, we take $R=$ $r_{0.5}$ according to Eq. (1) to derive $D_{H}$. This expresses a $\tau_{b}{ }^{1 / 3}$ dependence on the duration of hole burning, providing a straightforward means of controlling the size of the hole.

We note that this model of diffusion into a spherical well does not explicitly incorporate spin exchange or motional dynamics. Since these are modulated by settings such as the MAS rate and sample temperature, the set of model parameters we determine, including $D_{H}$, pertain to a specific set of experimental conditions. Our experiments have been carried out at a temperature around $95 \mathrm{~K}$, where significant molecular motion is frozen, and a magic-angle spinning rate of $3030 \mathrm{~Hz}$, much lower than the strongest ${ }^{1} \mathrm{H}-{ }^{1} \mathrm{H}$ dipolar coupling frequencies. This prevents the suppression of spin diffusion by molecular motion and places us in a quasi-static regime where ${ }^{1} \mathrm{H}$ spin diffusion is not significantly affected (and may even be slightly enhanced) by sample rotation. ${ }^{20-21}$ 

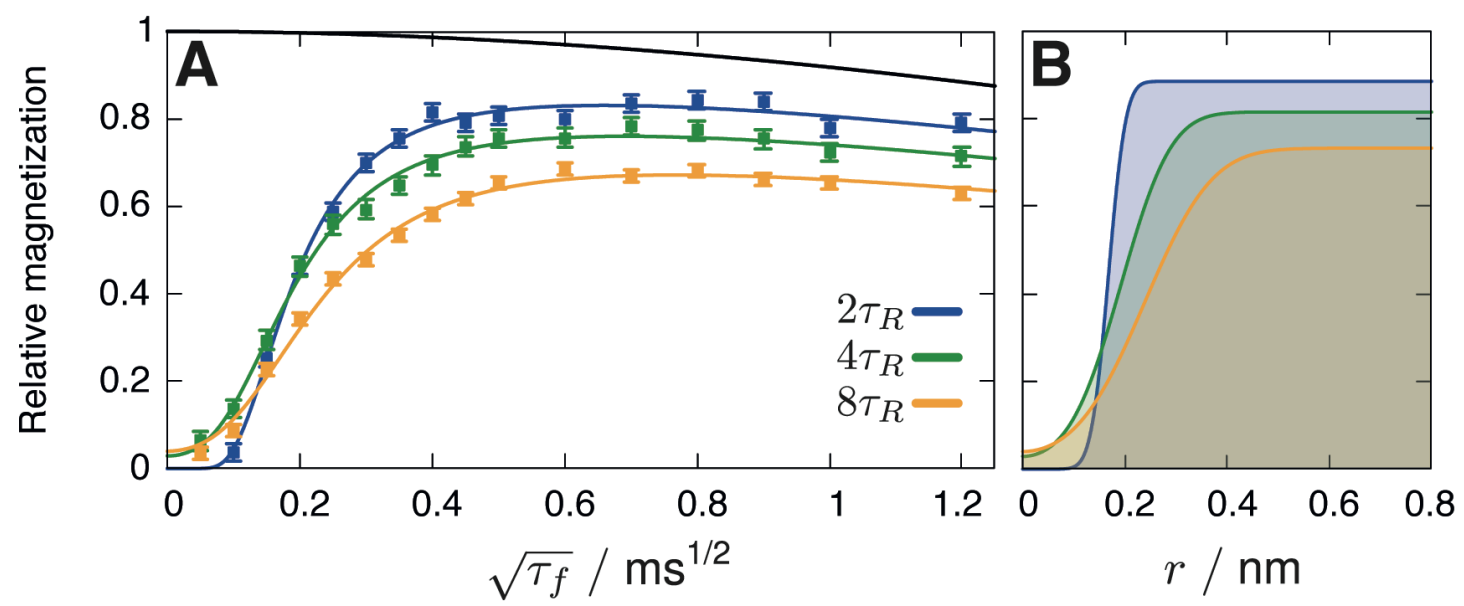

Figure 3. Profiles of ${ }^{1} \mathrm{H}$ magnetization for the hole-burning experiments for $20 \%{ }^{17} \mathrm{O}$-enriched tricalcium aluminate. A) Recovery of the ${ }^{17} \mathrm{O}$-detected ${ }^{1} \mathrm{H}$ signal intensities plotted as functions of the square root of the hole-filling interval $\tau_{f}$ for three values of $\tau_{b}$ : $0.66 \mathrm{~ms}\left(2 \tau_{R} ; 2\right.$ rotor periods at the $3030 \mathrm{~Hz}$ MAS rate), $1.32 \mathrm{~ms}\left(4 \tau_{R}\right)$, and $2.64 \mathrm{~ms}\left(8 \tau_{R}\right)$. The curves are best fits to the experimental data (points), according to the hole-filling model, Eq. (5). The intensities are relative to a reference experiment without ${ }^{17} \mathrm{O}$ REDOR pulses, in which case homonuclear ${ }^{1} \mathrm{H}$ decoupling is still applied but no hole is burned. The black line corresponds to the recovery limit based upon a component of spin relaxation with time constant $T_{1}=11.7 \mathrm{~ms}$. B) Simulated radial magnetization profiles immediately after hole burning $\left(\tau_{f}=0\right)$, corresponding to $M(r, 0)$, using parameters from the best-fit analysis. The sample temperature was near $95 \mathrm{~K}$.

To selectively monitor the magnetization near the center of the hole and validate the use of Eq. (5), we used a very short $(10 \mu \mathrm{s})$ cross-polarization (CP) contact time, with offresonance ${ }^{1} \mathrm{H}$ irradiation in the manner of Lee and Goldburg $^{17}$ for additional suppression of proton spin diffusion during the $\mathrm{CP}$ transfer. Such a short contact time transfers polarization between only the most strongly dipole-coupled nuclei, which are those ${ }^{1} \mathrm{H}$ nuclei within a few bond lengths of the ${ }^{17} \mathrm{O}$ nucleus at the center of each spherical well.

The magnetization recovery data and the best fit to $M_{c}\left(\tau_{f}\right)$ given by Eq. (5) for $\mathrm{Ca}_{3} \mathrm{Al}_{2} \mathrm{O}_{6}$ hydrated with $20 \%$ ${ }^{17} \mathrm{O}$-enriched water for $24 \mathrm{~h}$ are plotted in Figure 3A. The parameters $M_{2}, \Delta t, T$, and $D_{H}$ in Eq. (5) were determined as a part of the numerical fit. More details regarding the samples (including ${ }^{17} \mathrm{O}$ enrichment levels after hydration) and fitting procedure are given in the supplementary information (SI). The SI also shows analogs of Figure 3A for the $\mathrm{Ca}_{3} \mathrm{Al}_{2} \mathrm{O}_{6}$ sample hydrated with $3 \%{ }^{17} \mathrm{O}$-enriched water for $24 \mathrm{~h}$ and a $\mathrm{Ca}_{3} \mathrm{SiO}_{5}$ sample hydrated with $5 \%{ }^{17} \mathrm{O}$-enriched water for $50 \mathrm{~d}$. Our analysis of $\mathrm{Ca}_{3} \mathrm{SiO}_{5}$ is complicated by the fact that it is known to form mixtures of poorly-ordered calcium silicate hydrate (C-S-H) as well as crystalline $\mathrm{Ca}(\mathrm{OH})_{2}$ upon hydration. In the SI, we show high-resolution ${ }^{17} \mathrm{O}$ spectra of our hydrated $\mathrm{Ca}_{3} \mathrm{SiO}_{5}$ sample (as well as the $\mathrm{Ca}_{3} \mathrm{Al}_{2} \mathrm{O}_{6}$ samples) and carry out a quantitative analysis which reveals that less than $20 \%$ of the ${ }^{17} \mathrm{O}$ is present as $\mathrm{Ca}(\mathrm{OH})_{2}$. Given the poor signal-to-noise ratios of our $\mathrm{Ca}_{3} \mathrm{SiO}_{5}$ datasets, our analysis should not be led into serious error by assuming our results pertain solely to the major hydration product, C-S-H.
We see that Eq. (5) leads to excellent fits of three datasets acquired for hole-burning intervals of $0.66 \mathrm{~ms}, 1.32 \mathrm{~ms}$, and $2.64 \mathrm{~ms}$, corresponding to $I_{0.5}$ values of $0.17 \mathrm{~nm}, 0.22 \mathrm{~nm}$, and $0.27 \mathrm{~nm}$ from Eq. (1). Signal intensities near zero were recorded for filling intervals less than $10 \mu \mathrm{s}$, validating the constraint $M_{1}=0$. For $\tau_{f}>10 \mu \mathrm{s}$, there is onset of rapid recovery of the magnetization toward $M_{2}$, which represents the volume average proton polarization after hole burning. Measured with respect to a reference experiment in which the ${ }^{17} \mathrm{O}$ dephasing pulses are deactivated and no holes are burned in the proton polarization, we should expect $M_{2}<$ 1 , with the value of unity obtained only in the limit of infinite ${ }^{17} \mathrm{O}$ dilution. This recovery limit is indicated by the black line in Figure 3A, and indeed we see that in the case of hydrated $\mathrm{Ca}_{3} \mathrm{Al}_{2} \mathrm{O}_{6}$ the intensities do not reach this limit. Rather, we find decreasing $M_{2}$ values of $0.88,0.81$, and 0.73 for increasing durations of hole burning. For otherwise identically hydrated $\mathrm{Ca}_{3} \mathrm{Al}_{2} \mathrm{O}_{6}(3 \%)$, we find much lower respective $M_{2}$ values of $1.00,0.94$, and 0.91 . This trend versus $\tau_{b}$ corresponds to $(-7.5 \pm 1.1) \% / \mathrm{ms}$ for $\mathrm{Ca}_{3} \mathrm{Al}_{2} \mathrm{O}_{6}(20 \%)$ and $(-4.5 \pm 1.6) \% / \mathrm{ms}$ for $\mathrm{Ca}_{3} \mathrm{Al}_{2} \mathrm{O}_{6}(3 \%)$. The ratio of these values $(20 \%$ over $3 \%)$ is only 1.7 , yet the ratio of ${ }^{17} \mathrm{O}$ concentrations is 6.7. This is consistent with incipient hole overlap for the $\mathrm{Ca}_{3} \mathrm{Al}_{2} \mathrm{O}_{6}(20 \%)$ sample, even at the shortest holeburning intervals used here. Further discussion pertaining to hole overlap leading to less than expected destruction of average proton polarization is given in the $\mathrm{SI}$. For the $\mathrm{Ca}_{3} \mathrm{SiO}_{5}$ sample, which has a lower ${ }^{17} \mathrm{O}$ concentration than $\mathrm{Ca}_{3} \mathrm{Al}_{2} \mathrm{O}_{6}$, is it difficult to assess whether $M_{2}$ departs from unity because of low signal-to-noise ratios and so here we fit with the constraint $M_{2}=1$, as described in the SI. 
From the full solution of Eq. (3), we can also calculate initial magnetization profiles $M(r, 0)$ in the context of the analytic model for each value of $\tau_{b}$, which is shown in Figure 3B using parameters determined from the best fit analysis. The appearance of nonzero magnetization at $r=0$ may appear in contradiction to the constraint $M_{1}=0$, but in fact this is a consequence of the advancement parameter increasing from $2 \mu$ s to $13 \mu \mathrm{s}$ to $22 \mu \mathrm{s}$ with increasing $\tau_{b}$. This accounts for the decreasing slope of the hole edge and reflects the fact that we are not truly sampling the ${ }^{1} \mathrm{H}$ magnetization at the single point $r=0$, but rather over a small neighborhood near $r=0$, over which the integrated signal intensity tends to a small but nonzero value for sufficiently large (but finite) holes, even for ideal dipolar dephasing. Residual spin diffusion during hole burning may also contribute.

Table 1. Proton spin diffusion coefficients, $D_{H} / \mathrm{nm}^{2} \mathrm{~s}^{-1}$, for hydrated $\mathrm{Ca}_{3} \mathrm{Al}_{2} \mathrm{O}_{6}$ and hydrated $\mathrm{Ca}_{3} \mathrm{SiO}_{5}$ with different extents of ${ }^{17} \mathrm{O}$ enrichments, determined for different hole burning intervals.

\begin{tabular}{|c|c|c|c|c|}
\hline \multirow{2}{*}{ Sample } & \multicolumn{4}{|c|}{ Hole burning interval } \\
\cline { 2 - 5 } & $2 \tau_{R}$ & $4 \tau_{R}$ & $8 \tau_{R}$ & $\infty$ \\
\hline $\begin{array}{c}\mathrm{Ca}_{3} \mathrm{Al}_{2} \mathrm{O}_{6} \\
(20 \%)\end{array}$ & $156 \pm 11$ & $204 \pm 15$ & $222 \pm 12$ & $245 \pm 4$ \\
\hline $\begin{array}{c}\mathrm{Ca}_{3} \mathrm{Al}_{2} \mathrm{O}_{6} \\
(3 \%)\end{array}$ & $165 \pm 11$ & $200 \pm 13$ & $214 \pm 11$ & $232 \pm 2$ \\
\hline $\begin{array}{c}\mathrm{Ca}_{3} \mathrm{SiO}_{5} \\
(5 \%)\end{array}$ & $71 \pm 7$ & $105 \pm 12$ & $120 \pm 12$ & $137 \pm 2$ \\
\hline
\end{tabular}

The behaviors of the $M_{2}$ and $\Delta t$ parameters are consistent with expectations, increasing our confidence that $D_{H}$ should behave similarly. The proton spin diffusion coefficients we determine by our analysis for each of the samples are given in Table 1. The proton concentrations, $\mathcal{c}$, of hydrated $\mathrm{Ca}_{3} \mathrm{SiO}_{5}$ and hydrated $\mathrm{Ca}_{3} \mathrm{Al}_{2} \mathrm{O}_{6}$ are around $20 \mathrm{M}$ and $90 \mathrm{M}$, respectively. Assuming that $D_{H} \propto c^{1 / 3}, 25-26$ we would expect $D_{H}$ for hydrated $\mathrm{Ca}_{3} \mathrm{SiO}_{5}$ to be about $60 \%$ of that for hydrated $\mathrm{Ca}_{3} \mathrm{Al}_{2} \mathrm{O}_{6}$, which is consistent with the values shown in Table 1.

Rather than exhibiting behaviors that are independent of $\tau_{b}$, we observe in Table 1 that the spin diffusion coefficients $D_{H}$ increase with the duration of hole burning $\tau_{b}$. This effect is consistent across the different samples. This phenomenon was also observed by Chen and Schmidt-Rohr in their ${ }^{13} \mathrm{C}$ hole-burning experiments on polymer samples, ${ }^{15}$ systems for which the results of the hole-burning method could be compared with techniques that were suitable over somewhat larger length scales (roughly $10 \mathrm{~nm}$ ). They attributed such dependence on $\tau_{b}$ to anisotropic spin diffusion on nanometer length scales, and to a lesser extent on nondiffusive spin dynamics on microsecond time scales. The hole-burning method was found to underestimate $D_{H}$ compared to methods probing diffusion on larger length scales by a factor of about two or three, depending on the size of the hole. Given the tendencies for hydrated calcium aluminates and silicate to form clustered and layered structures, similar anisotropic effects may also be factors here.

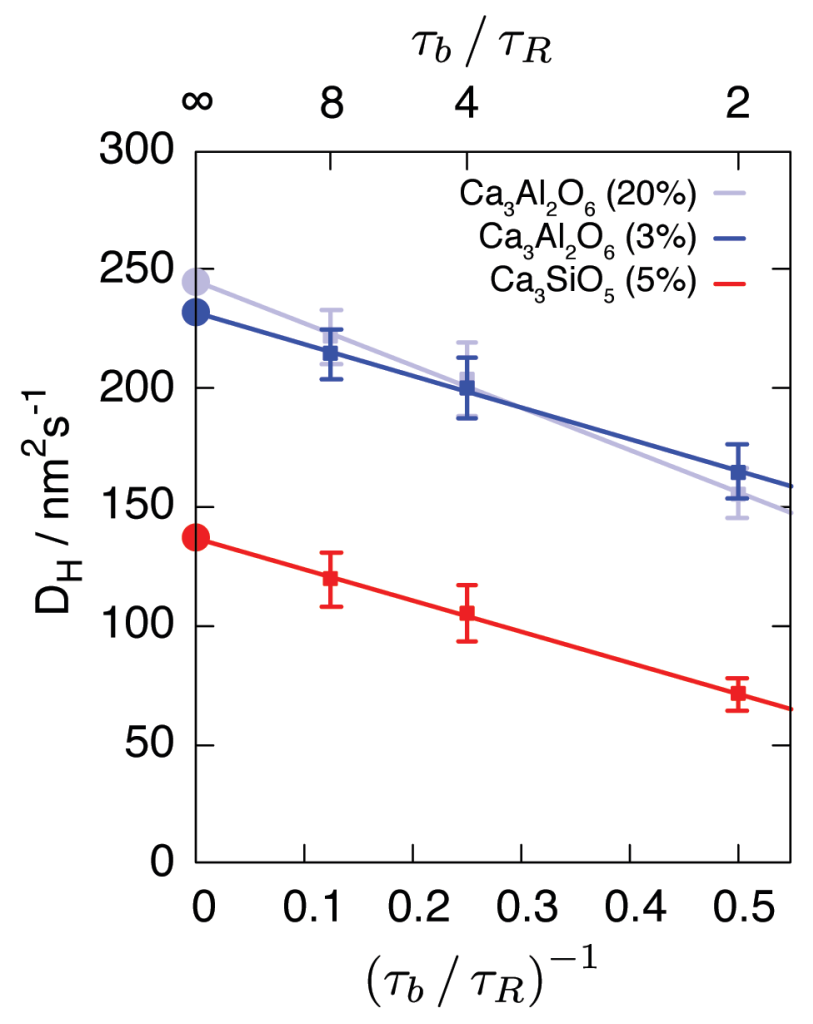

Figure 4. Plots of macroscopic proton spin diffusion coefficients $D_{H}$ versus hole-burning intervals $\tau_{b}$ for hydrated $\mathrm{Ca}_{3} \mathrm{Al}_{2} \mathrm{O}_{6}$ and hydrated $\mathrm{Ca}_{3} \mathrm{SiO}_{5}$ with different extents of ${ }^{17} \mathrm{O}$ enrichments obtained by extrapolation from finite hole burning intervals.

Ultimately, transport of a continuous proton magnetization by spin diffusion is a simple way to parameterize the very complicated spin exchange dynamics of protons in solids. By the parameterization of Eq. (3), the exchange dynamics during hole filling are such that diffusion genuinely appears to slow down as the sub-nanometer length scale is reached. Conversely, the difference between the diffusion coefficients we determine and the "macroscopic" proton spin diffusion coefficient, which we refer to as $D_{H}^{\infty}$, should diminish as the size of the hole increases. By plotting our $D_{H}$ values against $\tau_{b}^{-1}$, a linear relationship emerges for all of our samples, as shown in Figure 4. The intercept of the trendline corresponds to the bulk spin diffusivity $D_{H}^{\infty}$, which is given the rightmost column of Table 1 for the hydrated $\mathrm{Ca}_{3} \mathrm{Al}_{2} \mathrm{O}_{6}$ and $\mathrm{Ca}_{3} \mathrm{SiO}_{5}$ materials with different ${ }^{17} \mathrm{O}$ enrichments.

We find that $D_{H}^{\infty}$ is about twice the value of $D_{H}$ analyzed at the shortest hole-burning interval of $0.66 \mathrm{~ms}\left(2 \tau_{R}\right)$ for hydrated $\mathrm{Ca}_{3} \mathrm{SiO}_{5}$, and about 50\% larger for the hydrated 
$\mathrm{Ca}_{3} \mathrm{Al}_{2} \mathrm{O}_{6}$ materials. The values and trendlines for both the $3 \%$ and $20 \%{ }^{17} \mathrm{O}$-enriched $\mathrm{Ca}_{3} \mathrm{Al}_{2} \mathrm{O}_{6}$ samples cluster together; despite clear indications of hole merging at the $20 \%$ enrichment level ( vide supra), they have not yet reached levels where the diffusion coefficients we analyze are significantly affected. It would seem that our model, Eq. (5), compensates for the effect of hole merging primarily through the $M_{2}$ and $\Delta t$ parameters. Further research would indicate the concentration of hole-burning nuclei required to incur a significant error in apparent $D_{H}$.

The most significant source of uncertainty is a systematic one arising from the selection of $R$, which was defined by reasonable though somewhat arbitrary criteria. Instead of Eq. (1), the radius of natural dimensionality,

$$
r_{\text {nat }}=\sqrt[3]{Q \tau_{b}}
$$

could have been used. If we take $R=r_{\text {nat }}$ instead of $r_{0.5}$, then the diffusion coefficients we determine will be $\left(r_{\text {nat }} / r_{0.5}\right)^{2}=$ $86.2 \%$ of those reported in Table 1 . On this basis, we are confident in our values of $D_{H}$ to a level of $\pm 15 \%$. A better procedure may be to select fixed values of $R$ and $\Delta t$ by regression to the theoretical dephasing profile. We anticipate that this uncertainty could be reduced by investigating the performance of the pulse sequence under different homonuclear decoupling schemes (to change the scaling factor $\lambda_{c s}$ ) and faster sample rotation (to modulate spin diffusion). ${ }^{27-28}$

In summary, under quasi-static conditions such as the $3030 \mathrm{~Hz}$ magic-angle spinning used here, we determine the macroscopic proton spin diffusion coefficient should fall within $240 \pm 40 \mathrm{~nm}^{2} / \mathrm{s}$ for hydrated tricalcium aluminate and $140 \pm 20 \mathrm{~nm}^{2} / \mathrm{s}$ for hydrated tricalcium silicate. Physically, this means that proton magnetization is transported across space faster in hydrated tricalcium aluminate than in hydrated tricalcium silicate. We determined these values by hydrating with ${ }^{17} \mathrm{O}$-enriched water, which introduces spin labels that can be used to burn holes in the ${ }^{1} \mathrm{H}$ magnetization. The shape of the hole is well-described by dipolar dephasing principles and establishes boundary conditions for the return of magnetization into the hole by ${ }^{1} \mathrm{H}$ spin diffusion. The isotropic radial diffusion equation yields an approximate analytical solution to these boundary conditions, the validity of which is verified by our experimental measurements. The solution to the radial equation leads to an analytic expression for the recovery of magnetization in the hole which fits excellently to the experimental data. The model parameters determined by our analyses can be physically rationalized, including the positive correlation of the diffusion coefficient with the duration of hole burning.

These are the first measurements of spin diffusivity in silicates. Independent measurement of spin diffusivities allows the size of nanoscale domains to be determined with phase selectivity by, for example, magnetization relayed NMR methods. ${ }^{6,11}$ For silicates, this would permit tracking the appearance, size, and depth of the various hydrated phases that gradually form, crystallize, or react across the induction, acceleration, and deceleration stages of tricalcium silicate hydration. ${ }^{29}$ Our results thus provide crucial parameters and methodology for future work investigating such hydration processes.

\section{ASSOCIATED CONTENT}

\section{Supplementary Information}

A .pdf file providing sample details, additional NMR experimental and processing parameters, analysis of high-resolution ${ }^{17} \mathrm{O}$ spectra, reproducibility of results, fitting details, additional discussion regarding hole overlap, and the mathematics connecting Eq. (3) to Eq. (4).

\section{AUTHOR INFORMATION}

\section{Corresponding Author}

*lyndon.emsley@epfl.ch

\section{Notes}

There are no conflicts of interest.

\section{ACKNOWLEDGMENTS}

We would like to thank Dr. Arthur C. Pinon for insightful discussion. Zack Berkson provided assistance with samples. Funding provided by Swiss National Science Foundation Grant No. 200020_178860.

\section{REFERENCES}

1. Plassais, A.; Pomiès, M. P.; Lequeux, N.; Korb, J. P.; Petit, D.; Barberon, F.; Bresson, B. Microstructure Evolution of Hydrated Cement Pastes. Phys. Rev. E 2005, 72 (4), 041401.

2. Schmidt-Rohr, K.; Spiess, H. W. Multidimensional Solid-State NMR and Polymers. Academic Press: 1994.

3. Clauss, J.; Schmidt-Rohr, K.; Spiess, H. Determination of Domain Sizes in Heterogeneous Polymers by Solid-State NMR. Acta Polym. 1993, 44 (1), 1-17.

4. Hedesiu, C.; Demco, D. E.; Kleppinger, R.; Buda, A. A.; Blümich, B.; Remerie, K.; Litvinov, V. M. The Effect of Temperature and Annealing on the Phase Composition, Molecular Mobility and the Thickness of Domains in HighDensity Polyethylene. Polymer 2007, 48 (3), 763-777.

5. Huster, D.; Yao, X.; Hong, M. Membrane Protein Topology Probed by 'H Spin Diffusion from Lipids Using SolidState NMR Spectroscopy. J. Am. Chem. Soc. 2002, 124 (5), 874 883.

6. Pinon, A. C.; Schlagnitweit, J.; Berruyer, P.; Rossini, A. J.; Lelli, M.; Socie, E.; Tang, M.; Pham, T.; Lesage, A.; Schantz, S.; Emsley, L. Measuring Nano- to Microstructures from Relayed Dynamic Nuclear Polarization NMR. J. Phys. Chem. C 2017, 121 (29), 15993-16005.

7. Pinon, A. C.; Skantze, U.; Viger-Gravel, J.; Schantz, S.; Emsley, L. Core-Shell Structure of Organic Crystalline Nanoparticles Determined by Relayed Dynamic Nuclear Polarization NMR. J. Phys. Chem. A 2018, 122 (44), 8802-8807. 8. $\quad$ Hall, D. A.; Maus, D. C.; Gerfen, G. J.; Inati, S. J.; Becerra, L. R.; Dahlquist, F. W.; Griffin, R. G. Polarization- 
Enhanced NMR Spectroscopy of Biomolecules in Frozen Solution. Science 1997, 276 (5314), 930-932.

9. $\quad$ Lesage, A.; Lelli, M.; Gajan, D.; Caporini, M. A.; Vitzthum, V.; Miéville, P.; Alauzun, J.; Roussey, A.; Thieuleux, C.; Mehdi, A.; Bodenhausen, G.; Coperet, C.; Emsley, L. Surface Enhanced NMR Spectroscopy by Dynamic Nuclear Polarization. J. Am. Chem. Soc. 2010, 132 (44), 15459-15461.

10. Rossini, A. J.; Zagdoun, A.; Hegner, F.; Schwarzwälder, M.; Gajan, D.; Copéret, C.; Lesage, A.; Emsley, L. Dynamic Nuclear Polarization NMR Spectroscopy of Microcrystalline Solids. J. Am. Chem. Soc. 2012, 134 (40), 16899-16908.

11. Schlagnitweit, J.; Tang, M.; Baias, M.; Richardson, S.; Schantz, S.; Emsley, L. Nanostructure of Materials Determined by Relayed Paramagnetic Relaxation Enhancement. J. Am. Chem. Soc. 2015, 137 (39), 12482-12485.

12. Buda, A.; Demco, D. E.; Bertmer, M.; Blümich, B.; Reining, B.; Keul, H.; Höcker, H. Domain Sizes in Heterogeneous Polymers by Spin Diffusion using SingleQuantum and Double-Quantum Dipolar Filters. Solid State Nucl. Magn. Reson. 2003, 24 (1), 39-67.

13. Demco, D. E.; Johansson, A.; Tegenfeldt, J. Proton Spin Diffusion for Spatial Heterogeneity and Morphology Investigations of Polymers. Solid State Nucl.Magn. Reson. 1995, 4 (1), 13-38.

14. Schlagnitweit, J.; Tang, M.; Baias, M.; Richardson, S.; Schantz, S.; Emsley, L. A Solid-state NMR Method to Determine Domain Sizes in Multi-Component Polymer Formulations. $J$. Magn. Reson. 2015, 261, 43-48.

15. Chen, Q.; Schmidt-Rohr, K. Measurement of the Local H Spin-Diffusion Coefficient in Polymers. Solid State Nucl. Magn. Reson. 2006, 29 (1-3), 142-152.

16. Gullion, T.; Schaefer, J. Rotational-Echo DoubleResonance NMR. J. Magn. Reson. 1989, 81 (1), 196-200.

17. Lee, M.; Goldburg, W. I. Nuclear-Magnetic-Resonance Line Narrowing by a Rotating rf Field. Phys. Rev. 1965, 140 (4A), A1261-A1271.
18. Meiboom, S.; Gill, D. Modified Spin-Echo Method for Measuring Nuclear Relaxation Times. Rev. Sci. Instrum. 1958, 29 (8), 688-691.

19. Roos, M.; Micke, P.; Hempel, G. Monitoring Nuclear Spin-Flip Processes and Measuring Spin-Diffusion Constants via Hole Burning into the Magnetization. Chem. Phys. Lett. 2012, 536, 147-154.

20. Björgvinsdóttir, S.; Walder, B. J.; Pinon, A. C.; Emsley, L. Bulk Nuclear Hyperpolarization of Inorganic Solids by Relay from the Surface. J. Am. Chem. Soc. 2018, 140 (25), 7946-7951.

21. Roos, M.; Micke, P.; Saalwächter, K.; Hempel, G. Moderate MAS Enhances Local $\mathrm{H}$ Spin Exchange and Spin Diffusion. J. Magn. Reson. 2015, 260, 28-37.

22. Burum, D. P.; Rhim, W. K. Analysis of Multiple Pulse NMR in Solids. III. J. Chem. Phys. 1979, 71 (2), 944-956.

23. Fyfe, C. A.; Mueller, K. T.; Grondey, H.; Wong-Moon, K. C. Dipolar Dephasing Between Quadrupolar and Spin-1/2 Nuclei. REDOR and TEDOR NMR Experiments on VPI-5. Chem. Phys. Lett. 1992, 199 (1), 198-204.

24. Burum, D. P.; Linder, M.; Ernst, R. R. Low-Power Multipulse Line Narrowing in Solid-State NMR. J.Magn. Reson. 1981, 44 (1), 173-188.

25. Khutsishvili, G. R. Spin Diffusion. Sov. Phys. Uspekhi 1966, 8 (5), 743-769.

26. Wenckebach, W. T. Essentials of Dynamic Nuclear Polarization. Spindrift Publications: 2016.

27. Clough, S.; Gray, K. W. Spin Diffusion and Nuclear Magnetic Resonance in Rotating Solids. P. Phys. Soc. 1962, 80 (6), 1382.

28. Halse, M. E.; Zagdoun, A.; Dumez, J.-N.; Emsley, L. Macroscopic Nuclear Spin Diffusion Constants of Rotating Polycrystalline Solids from First-Principles Simulation. J. Magn. Reson. 2015, 254, 48-55.

29. Bullard, J. W.; Jennings, H. M.; Livingston, R. A.; Nonat, A.; Scherer, G. W.; Schweitzer, J. S.; Scrivener, K. L.; Thomas, J. J. Mechanisms of Cement Hydration. Cement Concrete Res. 2011, 41 (12), 1208-1223. 


\title{
Measurement of Proton Spin Diffusivity in Hydrated Cementitious Solids
}

\section{Supplementary Information}

\author{
Brennan J. Walder, ${ }^{\mathrm{a}}$ Nathan A. Prisco, ${ }^{\mathrm{b}}$ Federico M. Paruzzo, ${ }^{\mathrm{a}}$ Jayasubba Reddy Yarava, ${ }^{\mathrm{a}}$ \\ Bradley F. Chmelka, ${ }^{b}$ Lyndon Emsley ${ }^{a *}$

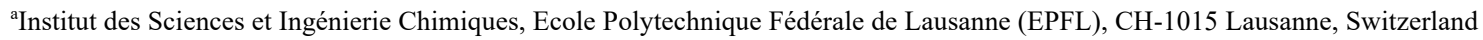 \\ ${ }^{b}$ Department of Chemical Engineering, University of California, Santa Barbara, California 93106, United States
}




\section{Sample information}

Anhydrous tricalcium aluminate $\left(\mathrm{Ca}_{3} \mathrm{Al}_{2} \mathrm{O}_{6}\right.$, Mineral Research Processing, France) was hydrated with either $20.9 \%{ }^{17} \mathrm{O}$-enriched water or $3.14 \%{ }^{17} \mathrm{O}$-enriched water for $24 \mathrm{~h}$ at $90{ }^{\circ} \mathrm{C}$, with a waterto-solids ratio of $1.00 \pm 0.05$. Anhydrous monoclinic tricalcium silicate $\left(\mathrm{Ca}_{3} \mathrm{SiO}_{5}\right.$, Mineral Research Processing, France) was hydrated with 5.23\% ${ }^{17} \mathrm{O}$-enriched water for $50 \mathrm{~d}$ at $25{ }^{\circ} \mathrm{C}$, with a water-to-solids ratio of $0.50 \pm 0.05$. The batches of $3.14 \%$ and $5.23 \%{ }^{17} \mathrm{O}$-enriched water were made by dilution of the $20.9 \%{ }^{17} \mathrm{O}$-enriched water with ordinary distilled water in a polyethylene vial; actual ${ }^{17} \mathrm{O}$ concentration was determined by mass measurements.

Hydration was initiated by vortex mixing $200 \mathrm{mg}$ of the dry solid the vial containing partially ${ }^{17} \mathrm{O}$-enriched water for 2 min and sealing the mixture under ambient atmosphere. After hydration, the samples were submerged in liquid $\mathrm{N}_{2}$ and lyophilized for $24 \mathrm{~h}$ at 0.10 Torr and $-40{ }^{\circ} \mathrm{C}$ to quench the hydration process and remove unreacted bulk or weakly adsorbed water. This workup method is not expected to influence the structure of the hydrated solids in any significant way. ${ }^{1}$ Upon hydration, $\mathrm{Ca}_{3} \mathrm{SiO}_{5}$, is known to form mixtures of poorly-ordered calcium silicate hydrates and $\mathrm{Ca}(\mathrm{OH})_{2} .{ }^{2}$ Hydration of $\mathrm{Ca}_{3} \mathrm{Al}_{2} \mathrm{O}_{6}$ in the absence of sulfates results in the formation of crystalline katoite, $\mathrm{Ca}_{3} \mathrm{Al}_{2}(\mathrm{OH})_{12}$, which is comprised of $\mathrm{Al}(\mathrm{VI})$ species as indicated by its ${ }^{27} \mathrm{Al}$ shift shown in Fig. S1B. The density of ${ }^{1} \mathrm{H}$ nuclei estimated from bulk densities and stoichiometry is generally between $15 \mathrm{M}$ and $30 \mathrm{M}$ for fully hydrated silicates and $88 \mathrm{M}$ for katoite. ${ }^{3}$
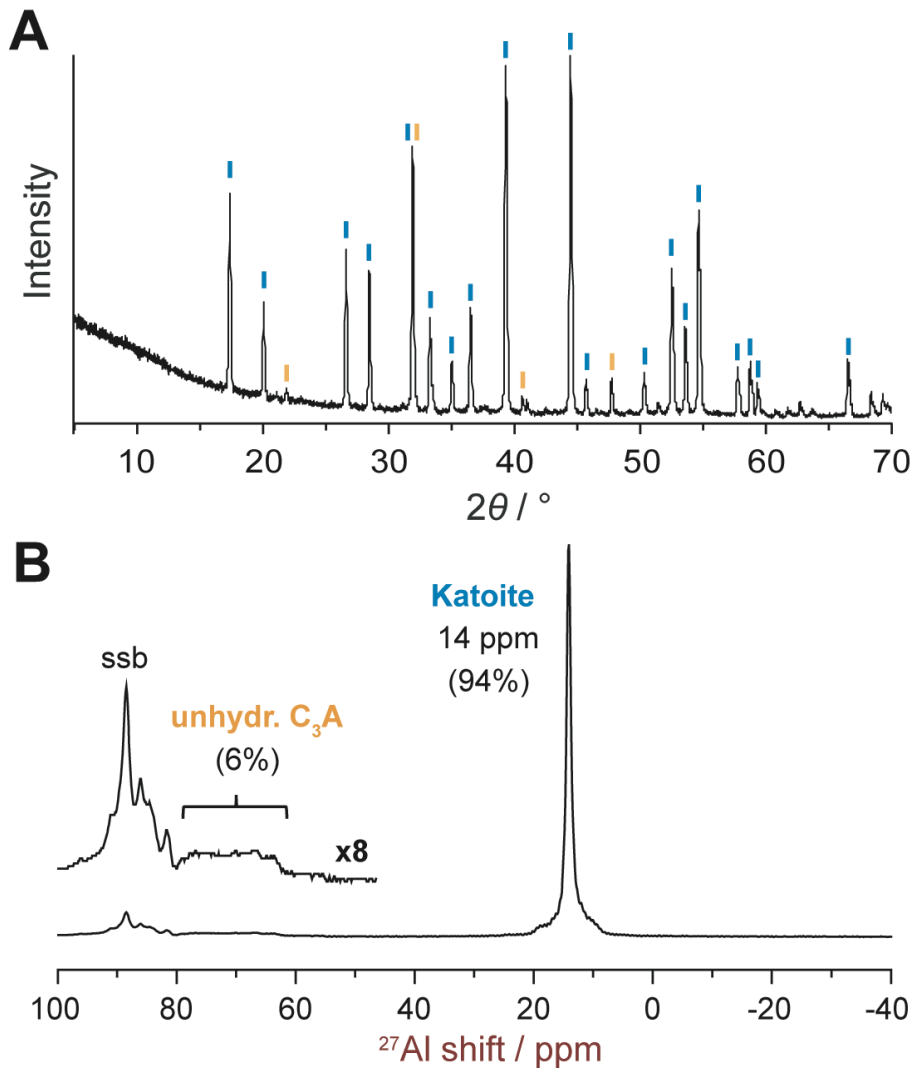

Figure S1. (A) Powder X-ray diffraction patterns with reflections indexed to $\mathrm{Ca}_{3} \mathrm{Al}_{2} \mathrm{O}_{6}$ (orange) and $\mathrm{Ca}_{3} \mathrm{Al}_{2}(\mathrm{OH})_{12}$ respectively. (B) Quantitative ${ }^{27} \mathrm{Al}$ solid-state $\mathrm{NMR}\left(18.8 \mathrm{~T}, 16 \mathrm{kHz}\right.$ MAS, $\left.25^{\circ} \mathrm{C}\right)$ of hydrated tricalcium aluminate indicating $\sim 94 \%$ conversion to $\mathrm{Ca}_{3} \mathrm{Al}_{2}(\mathrm{OH})_{12}$. 


\section{NMR parameters}

Hole burning experiments were performed on a Bruker 900 US $^{2}$ wide-bore Avance Neo NMR spectrometer operating at $21.14 \mathrm{~T}$, equipped with an HXY $3.2 \mathrm{~mm}$ DNP probe operating in ${ }^{1} \mathrm{H} /{ }^{17} \mathrm{O}$ double mode. Samples were restricted to the central third of a rotor with inner diameter of $2.2 \mathrm{~mm}$ in order to maximize rf homogeneity.

To measure spin diffusion coefficients the sequence shown in Figure 2 (main text) was used. All experiments were run at a rotational frequency of $3030 \mathrm{~Hz}$. BR24 was coded into a decoupling program (CPD) to ensure synchronization with the REDOR block, such that the cycle time of the decoupling was calculated to fit an integer number of full cycles inside the window permitted by the REDOR cycles. During BR24, the ${ }^{1} \mathrm{H}$ rf amplitude was $156.25 \mathrm{kHz}\left(90^{\circ}\right.$ pulse length of 1.6 $\mu \mathrm{s}$, transmitter power near $300 \mathrm{~W})$ and the length of the decoupling cycle $\left(\tau_{\mathrm{c}}\right)$ was near $82 \mu \mathrm{s}$. The spin diffusion coefficients were measured using REDOR dephasing periods of 2, 4, 8 and $16 \tau_{\mathrm{r}}$ (corresponding to $0.66,1.32,2.64$ and $5.28 \mathrm{~ms}$ ), and hole filling interval $\tau_{f}$ up to $1.44 \mathrm{~ms}$. For each REDOR dephasing time, sixteen reference spectra with $\tau_{f}$ of $1.44 \mathrm{~ms}$ (repeated to increase certainty of the recovery limit intensity) and without REDOR dephasing were acquired and used to normalize the intensities to a scale of relative magnetization. The transfer of the magnetization from ${ }^{1} \mathrm{H}$ to ${ }^{17} \mathrm{O}$ was done using LG-CP with a contact time of $10 \mu$ s in order to minimize spin diffusion and ensure the transfer is local, permitting the approximation that the signal observed corresponds to the center of the hole. Immediately prior to this, the ${ }^{1} \mathrm{H}$ magnetization was placed along the effective field with a $35^{\circ}$ pulse (skinny black bar labelled ' $\theta_{c}$ ' in the main text Figure 2). The sensitivity of the ${ }^{17} \mathrm{O}$ acquisition was improved by echo train acquisition using CPMG implementing central transition selective refocusing pulses. Twenty echoes, truncated to maximize sensitivity at the expense of resolution ${ }^{4}$ were acquired with an echo shift of one rotor period. For experiments at hole burning periods of 2, 4, 8 and $16 \tau_{\mathrm{r}}$, the following respective number of scans were collected:

20\% enriched C3A: 4, 8, 16, 40

$3 \%$ enriched C3A: $16,32,64,512$

5\% enriched C3S: $256,512,768,1536$

Reconstruction of CPMG data involved a matching procedure which exploited the sampling synchronicity of the windowed acquisition. The echo train was cut and appended as a function of echo count $k$. The amplitude of each data point comprising the $k^{\text {th }}$ echo by the filter function

$$
L\left(\tau_{k}\right)=\exp \left(-\left(\tau_{k} / T\right)^{\beta}\right),
$$

where $\tau_{k}$ is the time after excitation for the $k^{\text {th }}$ echo top and the parameters $T=5 \mathrm{~ms}$ and $\beta=0.77$ match the decay of the CPMG envelope. The $L\left(\tau_{k}\right)$ apodized echo dimension is summed out leaving the signal of an echo with a significant sensitivity enhancement. Processing of the reconstructed signal continued with partial integration of the ${ }^{17} \mathrm{O}$ line shape over the most intense points. No zero filling was used in this process. The resulting intensities were left as a function of normalized to noise. All spectral processing was carried out using the macOS application RMN, versions 1.8 .4 or $1.8 .6 .^{5}$ 


\section{Analysis of high-resolution ${ }^{17} \mathrm{O}$ spectra}

The high-resolution ${ }^{17} \mathrm{O}$ spectra of the hydrated tricalcium aluminate samples are shown in Figure S2. These spectra are typical of the MAS NMR powder pattern of a single ${ }^{17} \mathrm{O}$ site broadened by the second-order quadrupolar interaction. The spectra exhibit well-defined shoulders and sharp singularities, confirming the hydrated tricalcium aluminate phase corresponds to crystalline katoite, $\mathrm{Ca}_{3} \mathrm{Al}_{2}(\mathrm{OH})_{12}$.

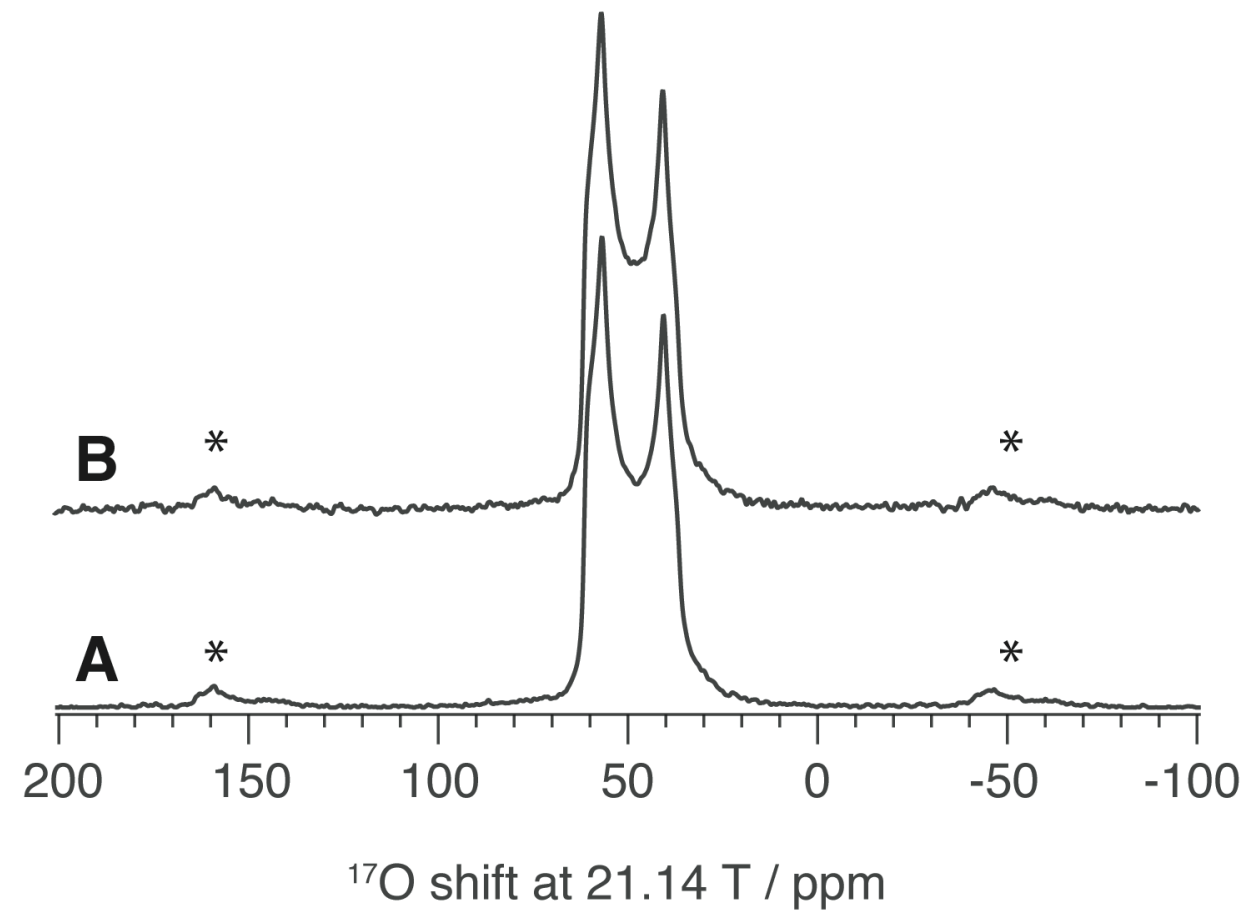

Figure S2. Direct excitation ${ }^{17} \mathrm{O}$ spectra at $21.14 \mathrm{~T}, 95 \mathrm{~K}$, and $12.5 \mathrm{kHz}$ MAS of (A) $\mathrm{Ca}_{3} \mathrm{Al}_{2} \mathrm{O}_{6}(20 \%)$ with 128 scans, $5 \mathrm{~s}$ recycle delay, (B) $\mathrm{Ca}_{3} \mathrm{Al}_{2} \mathrm{O}_{6}(3 \%)$ with 1024 scans, $2 \mathrm{~s}$ recycle delay. Proton decoupling with SPINAL64 and an rf amplitude of $125 \mathrm{kHz}$ was applied during acquisition. Approximate frequency referencing is given with respect to the ${ }^{1} \mathrm{H}$ spectrum of the $\mathrm{Ca}_{3} \mathrm{Al}_{2} \mathrm{O}_{6}(20 \%)$ sample assuming its maximum is at 4 ppm (split between water and hydroxyl type signals). Asterisks indicate spinning sidebands.

The hydration of tricalcium silicate is more complicated than tricalcium aluminate since calcium hydroxide is formed as a coexisting phase using our method of hydration. The high-resolution ${ }^{17} \mathrm{O}$ spectra of the hydrated tricalcium silicate sample is shown in Figure $\mathrm{S} 3$. This spectrum is dominated by broad features which were assigned to different C-S-H oxygen environments by Cong and Kirkpatrick: ${ }^{6}$ between 100 and 130 ppm (silicate nonbridging oxygens), 30 ppm and $80 \mathrm{ppm}$ (Ca-OH moieties and silicate bridging oxygens), and a low intensity tail going down to about $-40 \mathrm{ppm}$ (silanols and bound water). In addition to these broad features, the appearance of modest singularities at $44 \mathrm{ppm}$ and $62 \mathrm{ppm}$ correspond to ${ }^{17} \mathrm{O}$ in the secondary phase, crystalline $\mathrm{Ca}(\mathrm{OH})_{2}$. We quantify the fraction of ${ }^{17} \mathrm{O}$ in each phase by modeling the shift distribution of the environments of ${ }^{17} \mathrm{O}$ in $\mathrm{C}-\mathrm{S}-\mathrm{H}$ as three separate normal distributions, roughly corresponding to the regions described above. Fitting to a normal distribution is expected to be an adequate approximation for the C-S-H environments because the high magnetic field at which the measurements were performed reduces the skewedness of the line shape induced by the second- 
order quadrupolar interaction while at the same time amplifies the Gaussian broadening due to chemical shift disorder. The shift distribution of ${ }^{17} \mathrm{O}$ in $\mathrm{Ca}(\mathrm{OH})_{2}$ is modeled as MAS NMR powder pattern of a single ${ }^{17} \mathrm{O}$ site broadened by the second-order quadrupolar interaction. This powder pattern was calculated using $C_{q}=7.0 \mathrm{MHz}, \eta_{\mathrm{q}}=0$, and an isotropic chemical shift of $\delta_{\text {iso }}=74 \mathrm{ppm}$, in line with previously reported values. ${ }^{6}$ This fixes the shape and frequency distribution of the $\mathrm{Ca}(\mathrm{OH})_{2}$ signal, with only the amplitude allowed to vary. The shift, width, and amplitude of the normal distributions were allowed to vary freely. The result of the fit is shown as the decomposition shown in Figure S3. We see that $\mathrm{Ca}(\mathrm{OH})_{2}$ is a minor constituent, with $18 \%$ of the total ${ }^{17} \mathrm{O}$ present in this phase, leaving $82 \%$ present in the C-S-H. The residuals shown in Figure S3 appear as noise, improving the confidence in our parameterization.

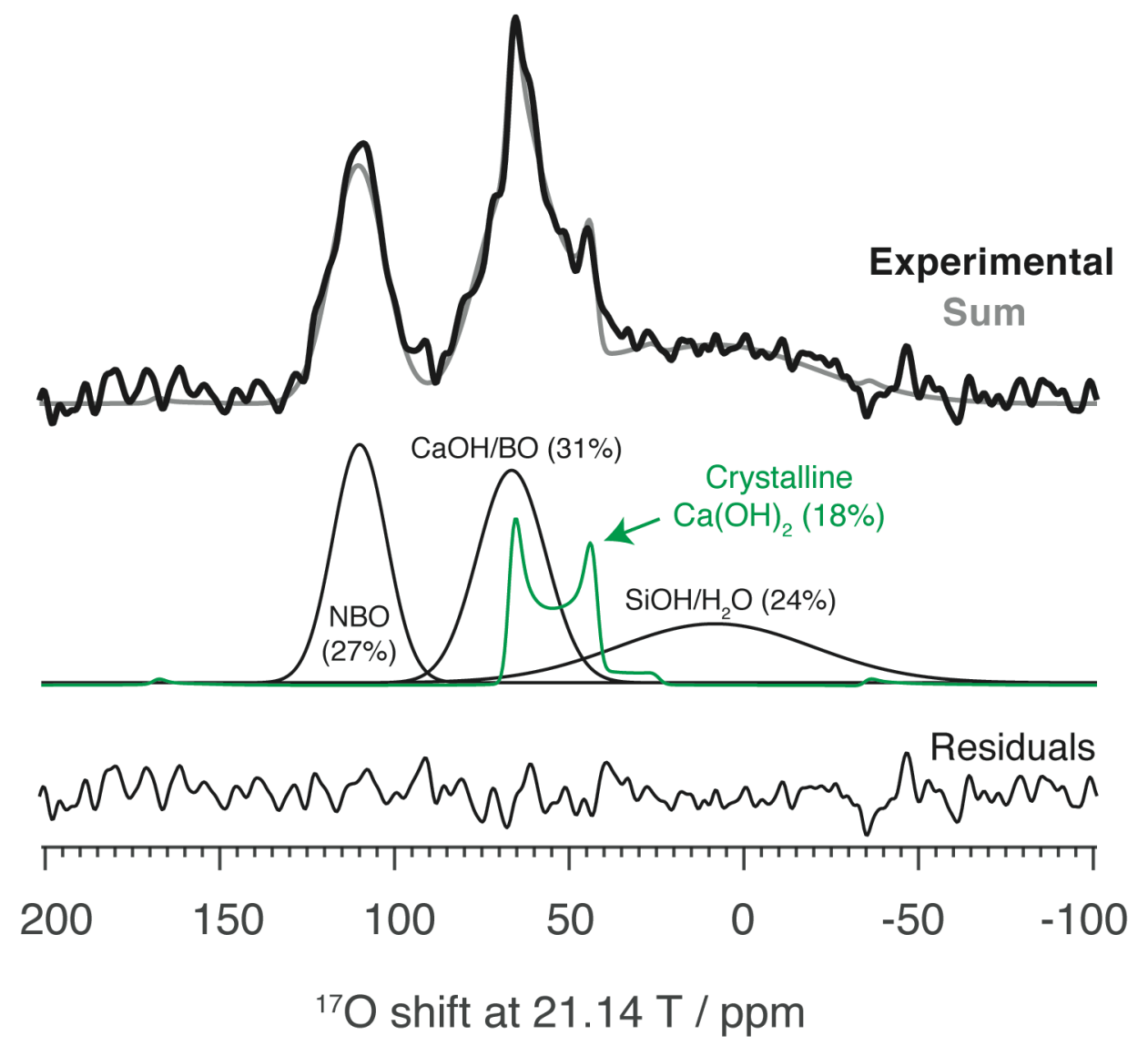

Figure S3. Quantitative decomposition of the high-resolution ${ }^{17} \mathrm{O}$ direct excitation MAS NMR spectrum of $\mathrm{Ca}_{3} \mathrm{SiO}_{5}$ (5\%) (top, black) into three Gaussian components (center, black) and a second-order quadrupole powder pattern (center, green). The former represents the ${ }^{17} \mathrm{O}$ environments in the poorly ordered calcium silicate hydrate phase whereas the latter corresponds to the spectrum of a coexisting crystalline $\mathrm{Ca}(\mathrm{OH})_{2}$ phase. The residuals (bottom) are the difference between the experimental spectrum and the sum of the calculated components (top, gray). The contribution of each component to the total area of the calculated spectrum is given in percent next to the corresponding oxygen species ( $\mathrm{NBO}$ - silicate non-bridging oxygen; $\mathrm{BO}$ - silicate bridging oxygen). Spectrum was acquired with 512 scans, $10 \mathrm{~s}$ recycle delay at $21.14 \mathrm{~T}, 95 \mathrm{~K}$, and $12.5 \mathrm{kHz}$ MAS. Proton decoupling with SPINAL64 and an $\mathrm{rf}$ amplitude of $125 \mathrm{kHz}$ was applied during acquisition. Approximate frequency referencing is given with respect to the ${ }^{1} \mathrm{H}$ spectrum of the $\mathrm{Ca}_{3} \mathrm{Al}_{2} \mathrm{O}_{6}(20 \%)$ sample by assuming its maximum is at $5 \mathrm{ppm}$. 


\section{Data reproducibility}

Owing to the high rf duty cycle of the hole burning pulse sequence (main text Figure 2), we occasionally observed bizarre behavior from circuit detuning in which the signal response of a repeating hole burning experiment would become erratic and/or diminish when the hole burning period exceeded $8 \tau_{R}$. This is illustrated in Figure S4 for repeated experiments at the shortest BR24 cycle time we could achieve that was commensurate with the $330 \mu$ s rotor period: $\tau_{\mathrm{c}} \approx 66 \mu \mathrm{s}$ (giving $\tau_{\mathrm{c}} / \tau_{\mathrm{R}} \approx 5$ ).

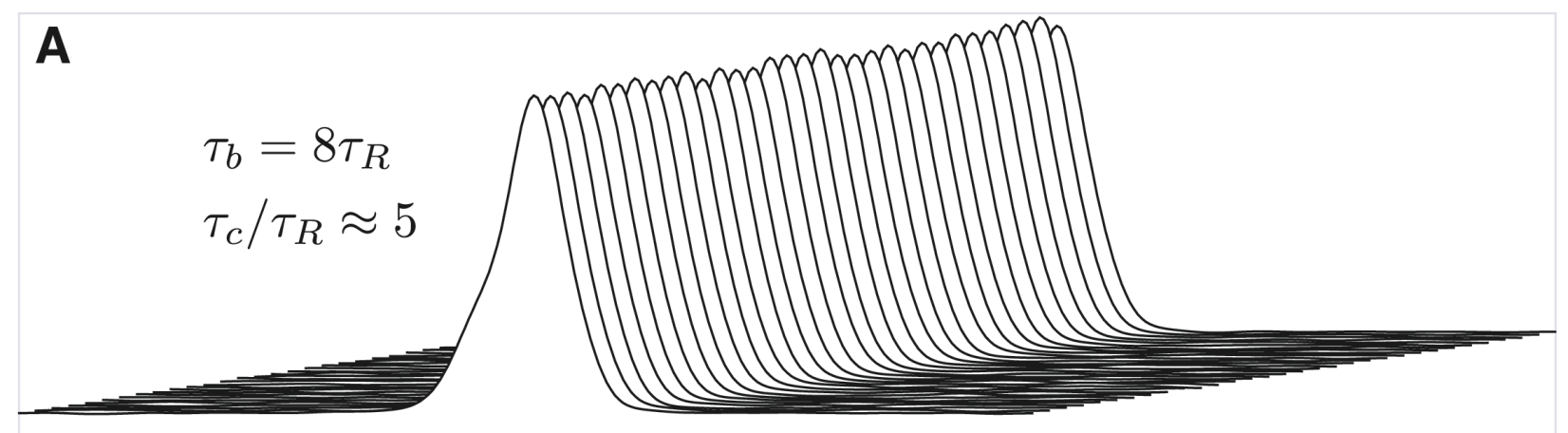

B

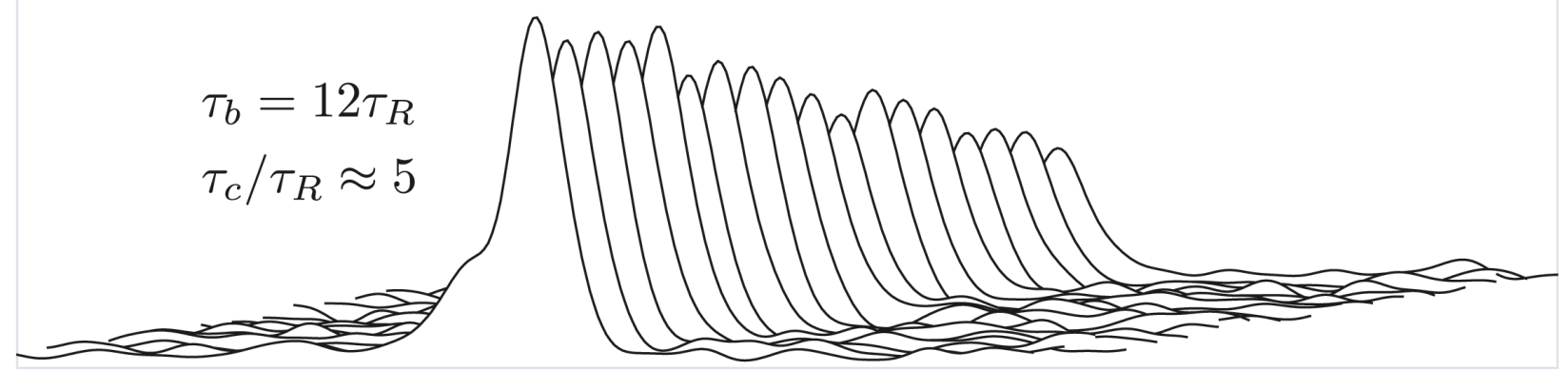

Figure S4. Reconstruction of (truncated) ${ }^{17} \mathrm{O}$ CPMG intensities for repeated hole burning experiments to test reproducibility. Horizontal axis is frequency and the span of each spectrum is constant. The first iteration of the experiment begins with the spectrum on the left. Sequentially to the right, each spectrum is the result of an identical hole burning experiment executed immediately following the preceding iteration. (A) Intensity profile of hole burning experiments at $\tau_{\mathrm{b}}=8 \tau_{R}(2.64 \mathrm{~ms})$ and $\tau_{\mathrm{c}} \approx 66 \mu \mathrm{s}$. The intensities of subsequent iterations are constant to within noise and the experiment is reproducible. (B) Intensity profile of hole burning experiments at a slightly longer $\tau_{\mathrm{b}}=12 \tau_{R}$ $(3.96 \mathrm{~ms})$ and the same $\tau_{\mathrm{c}} \approx 66 \mu \mathrm{s}$. The intensities of subsequent iterations diminish and reproducibility is lost.

For $\tau_{b}>8 \tau_{R}$ and $\tau_{\mathrm{c}} \approx 66 \mu \mathrm{s}$ it would often take minutes for the circuit to recover. Reproducibility was greatly improved by using a longer BR24 cycle time $\tau_{\mathrm{c}} \approx 82 \mu \mathrm{s}\left(\tau_{\mathrm{c}} / \tau_{\mathrm{R}} \approx 4\right)$ in which the decoupling pulse lengths and powers were unchanged but longer delays were incorporated into each decoupling period, thus reducing the duty cycle.

The experiment we analyze for diffusion coefficients use the longer $\tau_{\mathrm{c}} \approx 82 \mu \mathrm{s}$. No drop in decoupling efficiency relative to $\tau_{\mathrm{c}} \approx 66 \mu$ s was apparent. 


\section{Data analysis}

Data fitting was carried out using scripts written for gnuplot. The fit to the main text Eq. (5) was carried out in a multibranch fashion, fitting branches for each sample and at hole burning periods of $2,4,8$ and $16 \tau_{\mathrm{r}}$ simultaneously. Specific constraints were as follows:

Constraints across entire fit:

$T_{1}=11.713127 \mathrm{~ms}$ (determined from prior fit of main text Eq. (5) to the $\mathrm{Ca}_{3} \mathrm{Al}_{2} \mathrm{O}_{6}(20 \%)$ branch) $M_{1}=0$

$M_{2}=1$ (for $5 \% \mathrm{Ca}_{3} \mathrm{SiO}_{5}$ only, due to poorer $\mathrm{SNR}$ resulting from greater ${ }^{17} \mathrm{O}$ dilution)

$R\left(2 \tau_{R}\right)=0.1722 \mathrm{~nm}$ (constant used to return $D_{\mathrm{H}}$ from the characteristic diffusion time)

$R\left(4 \tau_{R}\right)=0.2170 \mathrm{~nm}$

$R\left(8 \tau_{R}\right)=0.2734 \mathrm{~nm}$

$R\left(16 \tau_{R}\right)=0.3444 \mathrm{~nm}$

Fit but constrained to be equal across sample branches:

Advancement parameters $\Delta t$ (property of hole burning; should be sample independent)

Free parameters for each sample and $\tau_{\mathrm{b}}$ :

$M_{2}$ (except for $\mathrm{Ca}_{3} \mathrm{SiO}_{5}(5 \%)$ as noted above)

$D_{\mathrm{H}}$

The results are given in the following table. We suggest that the fit errors reported in the table, insofar as they reflect upon uncertainty in the extrapolated "macroscopic" values of $D_{\mathrm{H}}$, are unimportant in comparison to the uncertainty in the selection of $R$.

\begin{tabular}{|c|c|c|c|c|c|}
\hline \multirow{2}{*}{ Parameter } & \multirow{2}{*}{ Sample } & \multicolumn{4}{|c|}{ Hole burning interval } \\
\cline { 3 - 6 } & & $2 \tau_{R}$ & $4 \tau_{R}$ & $8 \tau_{R}$ & $16 \tau_{R}$ \\
\hline \multirow{3}{*}{$D_{\mathrm{H}} / \mathrm{nm}^{2} \mathrm{~s}^{-1}$} & $\mathrm{Ca}_{3} \mathrm{Al}_{2} \mathrm{O}_{6}(20 \%)$ & $156 \pm 11$ & $204 \pm 15$ & $222 \pm 12$ & $268 \pm 24$ \\
\cline { 2 - 6 } & $\mathrm{Ca}_{3} \mathrm{Al}_{2} \mathrm{O}_{6}(3 \%)$ & $165 \pm 11$ & $200 \pm 13$ & $214 \pm 11$ & $264 \pm 23$ \\
\cline { 2 - 6 } & $\mathrm{Ca}_{3} \mathrm{SiO}_{5}(5 \%)$ & $71 \pm 7$ & $105 \pm 12$ & $120 \pm 12$ & $187 \pm 30$ \\
\hline \multirow{2}{*}{$M_{2} / \%$} & $\mathrm{Ca}_{3} \mathrm{Al}_{2} \mathrm{O}_{6}(20 \%)$ & $88.4 \pm 1.1$ & $81.5 \pm 1.3$ & $73.2 \pm 0.9$ & $65.4 \pm 1.5$ \\
\cline { 2 - 6 } & $\mathrm{Ca}_{3} \mathrm{Al}_{2} \mathrm{O}_{6}(3 \%)$ & $100.4 \pm 1.1$ & $94.5 \pm 1.1$ & $90.9 \pm 1.0$ & $76.1 \pm 1.6$ \\
\hline$\Delta t / \mu \mathrm{s}$ & & $2.2 \pm 1.6$ & $13.5 \pm 1.9$ & $22.1 \pm 2.1$ & $24.0 \pm 4.4$ \\
\hline
\end{tabular}

Table S1. Complete table of parameters determined by fitting the hole burning data to Eq. (5) of the main text, subject to the constraints described in this section. Error ranges corresponds to asymptotic standard errors reported by the goodness of fit routine.

Plots in the manner of the main text Figure 3 for all samples, and which includes the data for the hole burning interval $\tau_{b}=5.28 \mathrm{~ms}\left(16 \tau_{R}\right)$, are plotted below as Figure S5. 
$\mathrm{Ca}_{3} \mathrm{Al}_{2} \mathrm{O}_{6}$, hydrated with $20 \%{ }^{17} \mathrm{O}$-enriched water

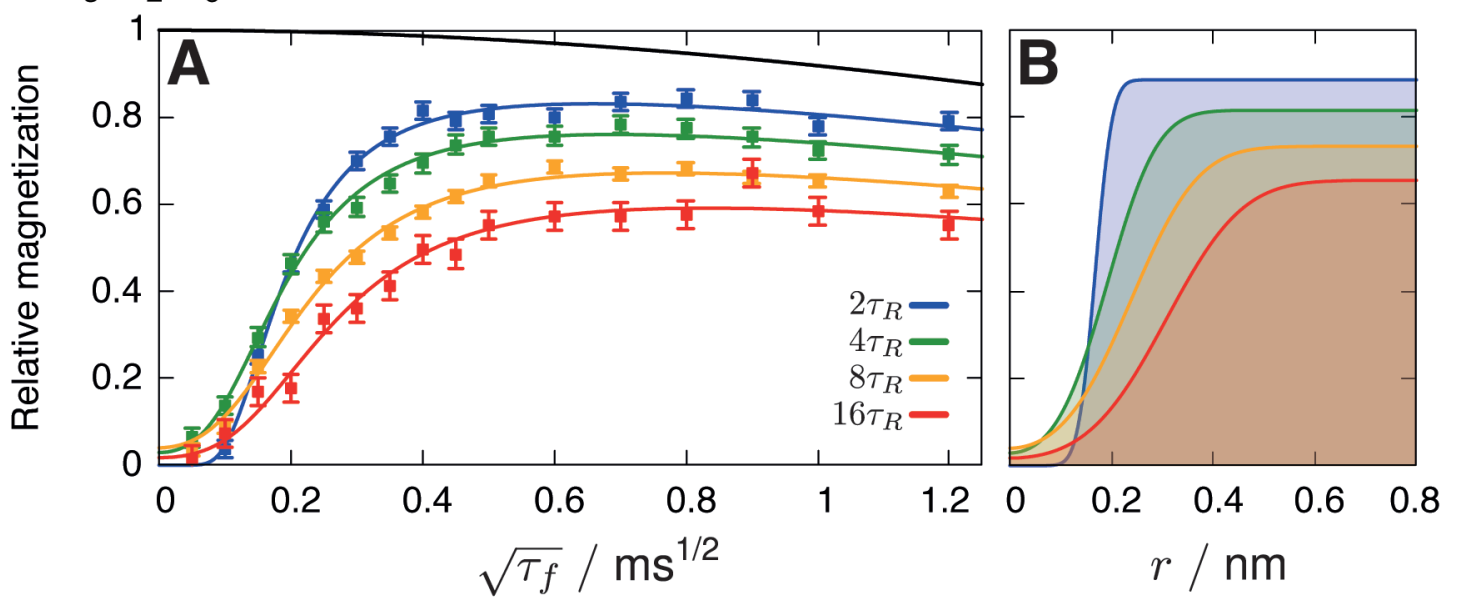

$\mathrm{Ca}_{3} \mathrm{Al}_{2} \mathrm{O}_{6}$, hydrated with $3 \%{ }^{17} \mathrm{O}$-enriched water

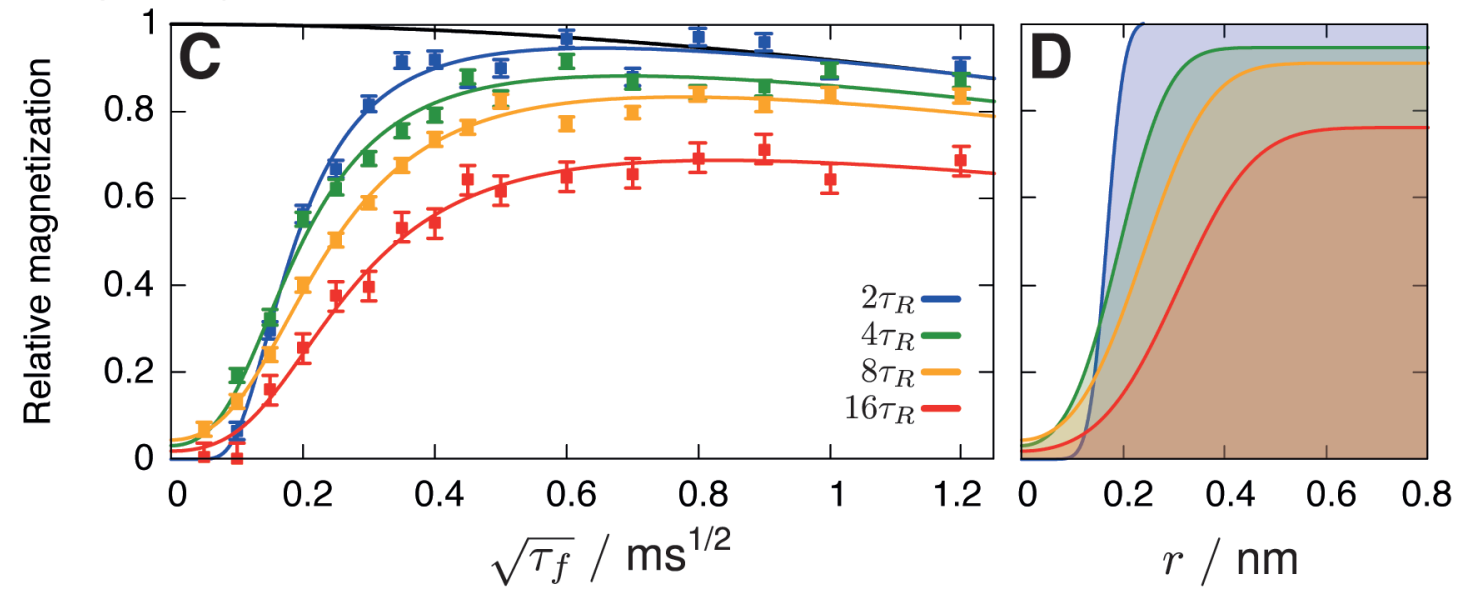

$\mathrm{Ca}_{3} \mathrm{SiO}_{5}$, hydrated with $5 \%{ }^{17} \mathrm{O}$-enriched water

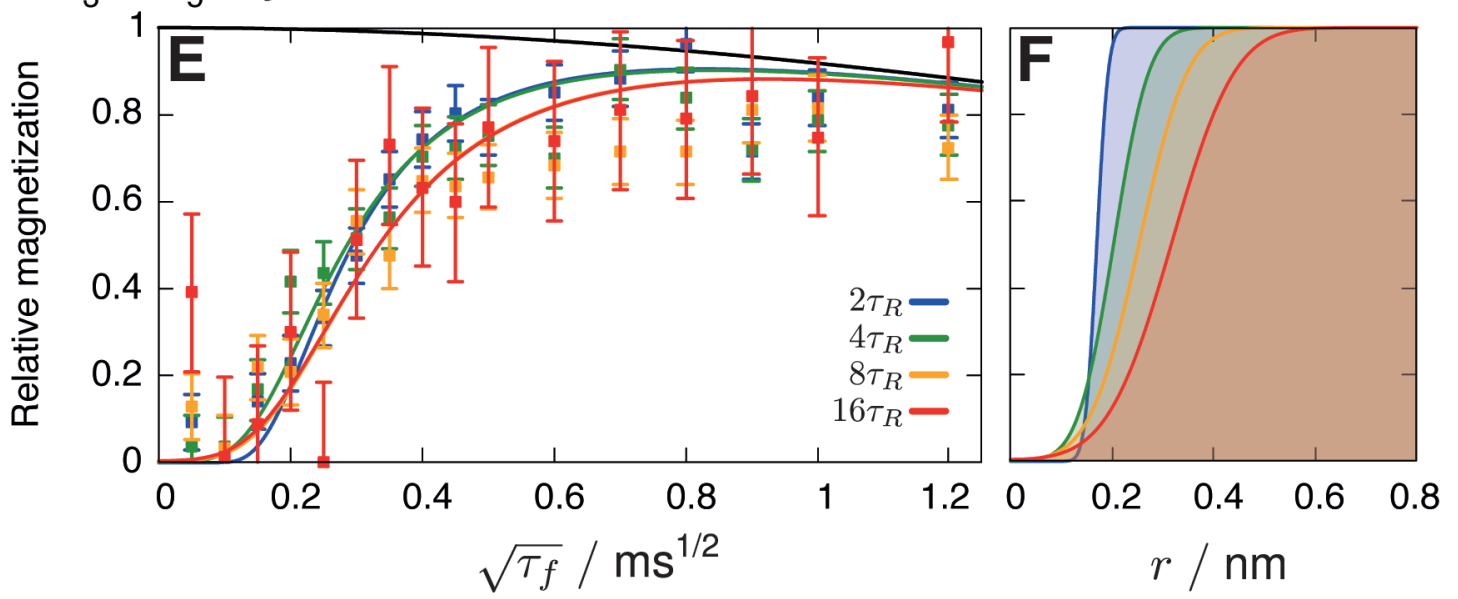

Figure S5. Temporal profiles of experiment hole filling recovery intensities, normalized to an experiment without REDOR pulses, for (A) $\mathrm{Ca}_{3} \mathrm{Al}_{2} \mathrm{O}_{6}(20 \%)$, (B) $\mathrm{Ca}_{3} \mathrm{Al}_{2} \mathrm{O}_{6}(3 \%)$, (C) $\mathrm{Ca}_{3} \mathrm{SiO}_{5}$ (5\%). Initial radial magnetization profiles in the model context are given in panels $\mathrm{B}, \mathrm{D}$, and $\mathrm{F}$, respectively for each sample. 
For reasons stated in section III above, we excluded the $16 \tau_{\mathrm{r}}$ data from our primary discussion. This data (at the lower duty cycle $\tau_{\mathrm{c}} / \tau_{\mathrm{R}} \approx 4$ ) does not seem internally inconsistent, however, and should perhaps be included. We find that our results are not significantly affected if we include the $16 \tau_{\mathrm{r}}$ data in the extrapolation to infinite hole burning period, as shown in Figure S6 and Table S2. The consistently and anomalously high $D_{\mathrm{H}}$ we analyze in the $16 \tau_{\mathrm{r}}$ data, if legitimate, could indicate a transition to a regime where diffusion adopts a different character, perhaps due to the diminishing importance of nondiffusive spin dynamics or diffusion anisotropy at the larger hole sizes.

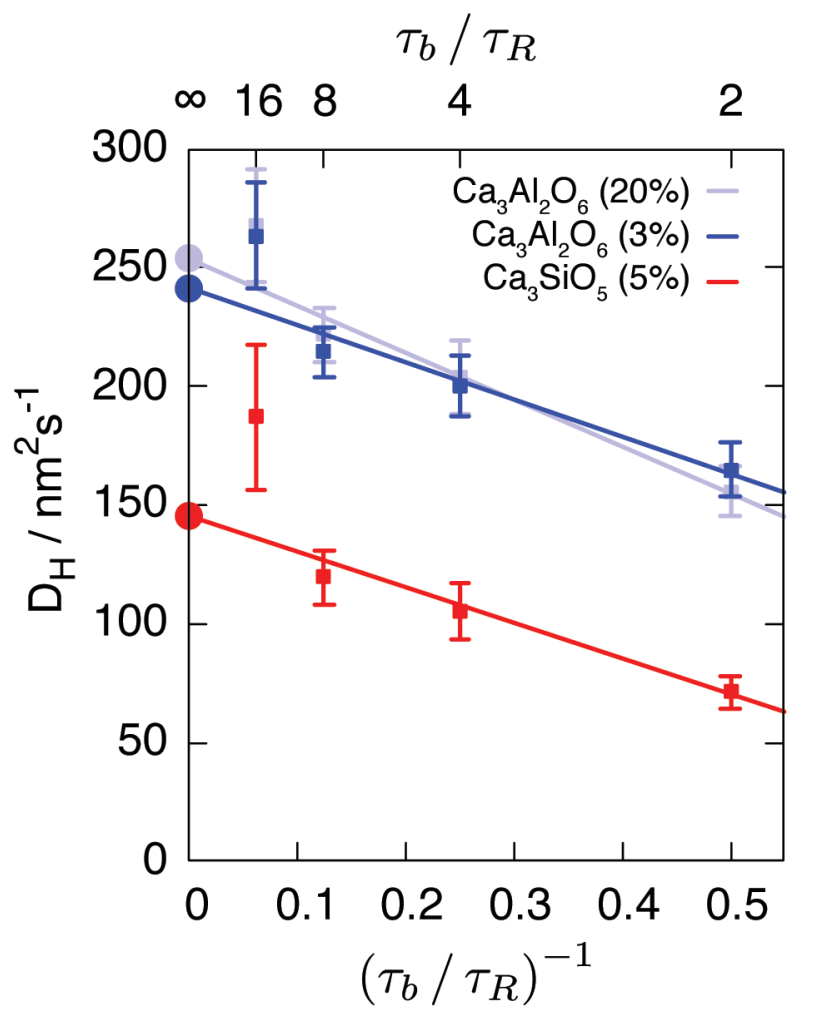

Figure S6. Determination of the macroscopic proton spin diffusion coefficients $D_{H}^{\infty}$ by extrapolation from finite hole burning intervals, including the parameters determined by analysis of the $16 \tau_{\mathrm{r}}$ data. The data points and error bars correspond to the parameters given in Table S1.

\begin{tabular}{|c|c|c|}
\hline Sample & $\begin{array}{c}D_{H}^{\infty} / \mathrm{nm}^{2} \mathrm{~s}^{-1} \\
\text { Excluding } 16 \tau_{R}\end{array}$ & $\begin{array}{c}D_{H}^{\infty} / \mathrm{nm}^{2} \mathrm{~s}^{-1} \\
\text { Including } 16 \tau_{R}\end{array}$ \\
\hline $\mathrm{Ca}_{3} \mathrm{Al}_{2} \mathrm{O}_{6}(20 \%)$ & $245 \pm 4$ & $254 \pm 12$ \\
\hline $\mathrm{Ca}_{3} \mathrm{Al}_{2} \mathrm{O}_{6}(3 \%)$ & $232 \pm 2$ & $242 \pm 14$ \\
\hline $\mathrm{Ca}_{3} \mathrm{SiO}_{5}(5 \%)$ & $137 \pm 2$ & $145 \pm 16$ \\
\hline
\end{tabular}

Table S2. Comparison of the macroscopic proton spin diffusion coefficients, $D_{H}^{\infty}$, between analyses which include and exclude the $16 \tau_{\text {r }}$ data. 


\section{Hole overlap}

In our model the $M_{2}$ coefficient can be physically interpreted in terms of hole overlap and the concentration of ${ }^{17} \mathrm{O}$ nuclei in the samples, according to

$$
M_{2}=\left(1-c_{S} V_{\text {hole }}\right)+M_{\Delta} \text {. }
$$

Here, $c_{S}$ is the number concentration of ${ }^{17} \mathrm{O}$ spins in the sample, $V_{\text {hole }}$ is the effective volume of a polarization hole due to dephasing, and $M_{\Delta}$ is defined as the excess fraction of unburned polarization. The quantity $\left(1-c_{S} V_{\text {hole }}\right)$ is the residual magnetization assuming all holes burn to the maximum extent of their capability, which is the case when holes do not overlap. We therefore expect $M_{\Delta}>0$ as shared hole volume permits an excess of unburned magnetization. In the limit of infinite ${ }^{17} \mathrm{O}$ dilution, and as hole volume shrinks, we expect $M_{\Delta} \rightarrow 0$.

The parameter $c_{S}$ can be calculated assuming the bulk density of katoite, $2.76 \mathrm{~g} / \mathrm{cm}^{3}$, the hydrated stoichiometry $\mathrm{Ca}_{3} \mathrm{Al}_{2} \mathrm{O}_{6}\left(\mathrm{H}_{2} \mathrm{O}\right)_{6}$, and completeness of oxygen exchange between water and tricalcium aluminate. Using the information in section $\mathrm{I}$, these assumptions lead to actual ${ }^{17} \mathrm{O}$ enrichment of $14.9 \%$ and $2.2 \%$ along with $c_{S}$ values of 7.87 nuclei $/ \mathrm{nm}^{3}$ and 1.18 nuclei $/ \mathrm{nm}^{3}$ for the nominally $\mathrm{Ca}_{3} \mathrm{Al}_{2} \mathrm{O}_{6}(20 \%)$ and $\mathrm{Ca}_{3} \mathrm{Al}_{2} \mathrm{O}_{6}(3 \%)$ samples, respectively. $V_{\text {hole }}$ is calculated assuming the effective radius of the spherical hole is determined by $r_{0.5}$.

In Fig S7A, experimentally derived values of the $M_{2}$ coefficient are plotted against $r_{0.5}$. The difference between the solid lines and the experimental data points is $M_{\Delta}$. For the $\mathrm{Ca}_{3} \mathrm{Al}_{2} \mathrm{O}_{6}(3 \%)$ sample, we see that $M_{2}$ coefficients cluster around the solid line, suggesting that hole overlap is not significant at this ${ }^{17} \mathrm{O}$ concentration. For the $\mathrm{Ca}_{3} \mathrm{Al}_{2} \mathrm{O}_{6}(20 \%)$ sample, however, we observe substantially nonzero values of $M_{\Delta}$, especially at $\tau_{b}=8 \tau_{R}$, when the hole volume is $0.086 \mathrm{~nm}^{3}$. This is consistent with our expectation that higher ${ }^{17} \mathrm{O}$ concentrations and larger hole volumes lead to more significant hole overlap.
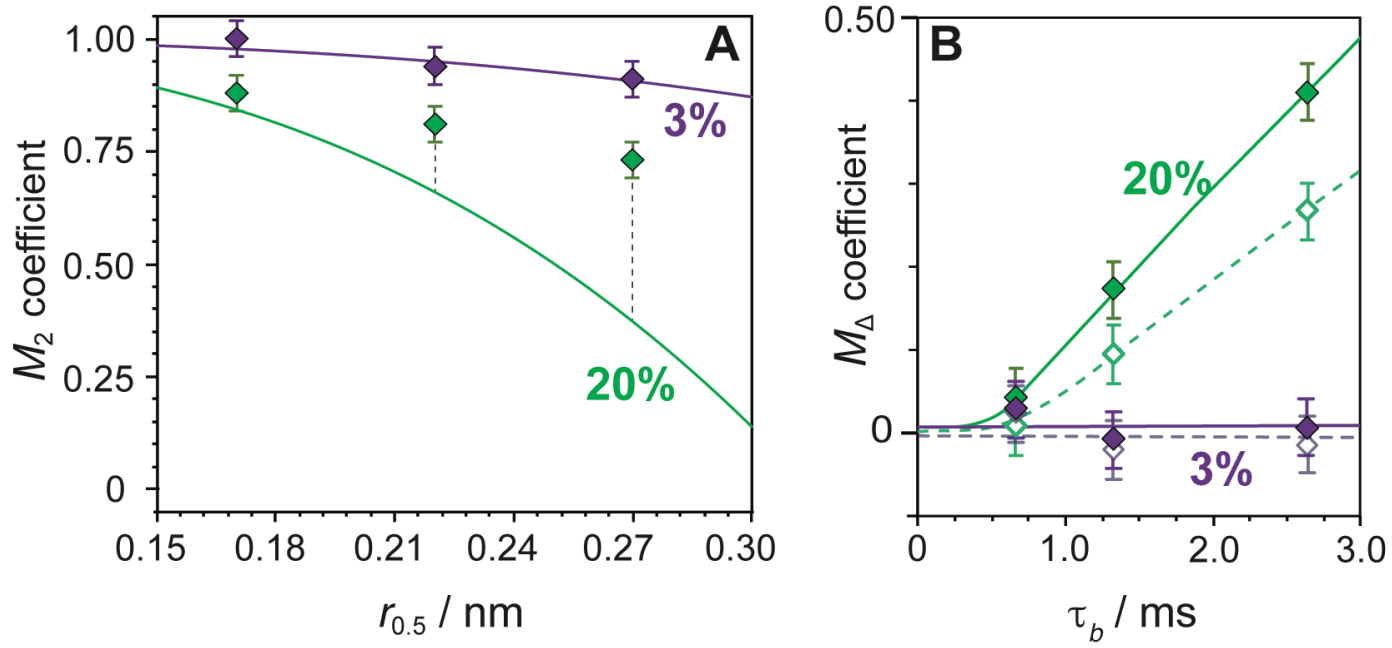

Figure S7. (A) Values of the $M_{2}$ coefficient versus hole size ( $\left.r_{0.5}\right)$ for the $3 \%$-enriched (purple) and 20\%-enriched (green) hydrated $\mathrm{Ca}_{3} \mathrm{Al}_{2} \mathrm{O}_{6}$. The solid lines are graphs of $\left(1-c_{S} V_{\text {hole }}\right)$, presenting a lower bound on $M_{2}$. Dashed vertical lines correspond to $M_{\Delta}$. (B) Excess fraction of unburned polarization, $M_{\Delta}$, for the two samples, plotted against the duration of hole burning. Filled and unfilled diamonds correspond to using $r_{0.5}$ and $r_{\text {nat }}$, respectively, to approximate the size of the hole. The solid $\left(r_{0.5}\right)$ and dashed $\left(r_{\text {nat }}\right)$ lines serve only to guide the eye. 
The excess fraction of unburned polarization we calculate also depends on the accuracy of the effective hole volume, $V_{\text {hole }}$. In Fig. S7B, we plot $M_{\Delta}$ for two sets of estimates for $V_{\text {hole }}$, one based upon $r_{0.5}$ and the other $r_{\text {nat }}$. The smaller hole size, $r_{\text {nat }}$, leads to smaller predicted values of $M_{\Delta}$. These results are summarized in Table S3.

\begin{tabular}{|c|c|c|c|c|c|}
\hline \multirow{2}{*}{ Sample } & \multirow{2}{*}{ Actual ${ }^{17} \mathrm{O}$ concentration } & \multicolumn{2}{|c|}{$R=r_{0.5}$} & \multicolumn{2}{c|}{$R=r_{\text {nat }}$} \\
\cline { 3 - 5 } & & $V_{\text {hole }} / \mathrm{nm}^{3}$ & $M_{\Delta} / \%$ & $V_{\text {hole }} / \mathrm{nm}^{3}$ & $M_{\Delta} / \%$ \\
\hline \multirow{3}{*}{$\mathrm{Ca}_{3} \mathrm{Al}_{2} \mathrm{O}_{6}(20 \%)$} & 0.0214 & 5.2 & 0.0171 & 1.9 \\
& \multirow{3}{*}{$14.9 \%$} & 0.0428 & 15.2 & 0.0342 & 8.4 \\
\hline \multirow{3}{*}{$\mathrm{Ca}_{3} \mathrm{Al}_{2} \mathrm{O}_{6}(3 \%)$} & \multirow{3}{*}{$2.24 \%$} & 0.0856 & 40.6 & 0.0685 & 27.1 \\
\cline { 3 - 6 } & & 0.0214 & 2.9 & 0.0171 & 2.4 \\
\cline { 3 - 6 } & & 0.0428 & -0.4 & 0.0342 & -1.5 \\
\cline { 3 - 6 } & & 0.0856 & 1.0 & 0.0685 & -1.0 \\
\hline
\end{tabular}

Table S3. Numerical values of $M_{\Delta}$ for the hydrated tricalcium aluminate samples, calculated for two sets of effective hole radii and three different hole burning intervals. Estimated $2 \sigma$ uncertainties for the $M_{\Delta}$ are $\pm 3 \%$. 


\section{General solution of the radial diffusion equation for the spherical well}

We are solving the three-dimensional isotropic diffusion equation, Eq. (3) of the main text

$$
\frac{\partial M}{\partial t}=D \nabla^{2} M
$$

with $M \equiv M(r, \theta, \phi, t)$, and the diffusion coefficient $D$, for the initial value problem

$$
\begin{gathered}
M(r, 0)=\left\{\begin{array}{l}
M_{1} \text { if } r<R, \\
M_{2} \text { if } r>R,
\end{array}\right. \\
\left.\frac{\partial M}{\partial r}\right|_{r=0}=0, \forall t, \\
\lim _{r \rightarrow \infty} M(r, t)=M_{2}, \forall t,
\end{gathered}
$$

and $M$ is independent of $\theta$ and $\phi$. Eq. (3) can be transformed into the homogenous Helmholtz equation,

$$
\left(\nabla^{2}+k^{2}\right) g=0
$$

where $g \equiv g(r, \theta, \phi)$, is stripped of its time-dependence by its relation to the "normal modes"

$$
M_{k}(r, \theta, \phi, t)=g_{k}(r, \theta, \phi) e^{-D k^{2} t}
$$

indexed by the eigenvalue $k$, which has units of inverse length.

The solutions to the homogeneous Helmholtz equation for cases of spherical symmetry are given by the spherical wave solutions $g_{k}(r)=e^{-i k r} / r$. From this we have the general solution

$$
M(r, t)=\int_{-\infty}^{+\infty} A(k) \frac{e^{-i k r}}{r} e^{-D k^{2} t} d k
$$

The combination of modes which solves the initial value problem is given by the function $A(k)$. There is no need to solve for $A(k)$ in terms of $k$, as the above equation can be transformed into

$$
M(r, t)=M_{2}+\frac{M_{1}-M_{2}}{\sqrt{4 \pi D t}} \frac{1}{r} \int_{-R}^{+R} r^{\prime} e^{-\frac{\left(r-r^{\prime}\right)^{2}}{4 D t}} d r^{\prime}
$$

by use of the convolution theorem of Fourier transforms and application of the boundary conditions. The integral in this expression can be evaluated to yield the analytic solution

$$
M(r, t)=M_{2}+\frac{M_{1}-M_{2}}{2}\left[\left(\operatorname{erf}\left(\frac{r+R}{\sqrt{4 D t}}\right)-\operatorname{erf}\left(\frac{r-R}{\sqrt{4 D t}}\right)\right)+\sqrt{\frac{4 D t}{\pi}} \frac{1}{r}\left(e^{-\frac{(r+R)^{2}}{4 D t}}-e^{-\frac{(r-R)^{2}}{4 D t}}\right)\right]
$$

from which, upon taking the limit as $r \rightarrow 0$, we obtain Eq. (4) in the main text. 


\section{Additional references}

1. Rawal, A.; Smith, B. J.; Athens, G. L.; Edwards, C. L.; Roberts, L.; Gupta, V.; Chmelka, B. F. Molecular Silicate and Aluminate Species in Anhydrous and Hydrated Cements. J. Am. Chem. Soc. 2010, 132 (21), 7321-7337.

2. Pustovgar, E.; Sangodkar, R. P.; Andreev, A. S.; Palacios, M.; Chmelka, B. F.; Flatt, R. J.; Lacaillerie, J.-B. d. E. d. Understanding Silicate Hydration from Quantitative Analyses of Hydrating Tricalcium Silicates. Nat. Commun. 2016, 7, 10952.

3. Geng, G.; Myers, R. J.; Qomi, M. J. A.; Monteiro, P. J. M. Densification of the Interlayer Spacing Governs the Nanomechanical Properties of Calcium-Silicate-Hydrate. Sci. Rep. 2017, 7 (1), 10986.

4. Dey, K. K.; Ash, J. T.; Trease, N. M.; Grandinetti, P. J. Trading Sensitivity for Information: Carr-Purcell-Meiboom-Gill Acquisition in Solid-State NMR. J. Chem. Phys. 2010, 133 (5), 054501.

5. PhySy Ltd, RMN, Version 1.8 (www.physyapps.com, PhySy Ltd., Grandview Heights, $\mathrm{OH}$ 43212).

6. Cong, X.; Kirkpatrick, R. J. ${ }^{17} \mathrm{O}$ MAS NMR Investigation of the Structure of Calcium Silicate Hydrate Gel. J. Am. Chem. Soc. 1996, 79 (6), 1585-1592. 